\title{
البحث الخغامس :
}

\section{أثر استزاتيجية الصف المقلوب في تنمية المفاهيه الفقهية والاتجاه

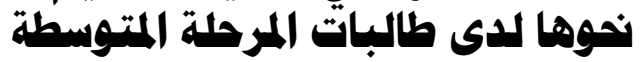 \\ بحث مستل من رسالت ماجستير بِ المناهج وطرق تلريس التربيت الإسلاميت}

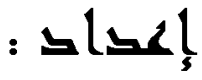

$$
\begin{aligned}
& \text { أ. مزة صنقور محمد الزهراني }
\end{aligned}
$$

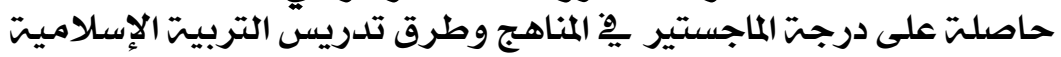

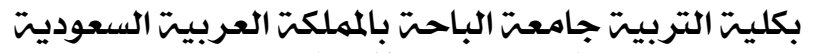

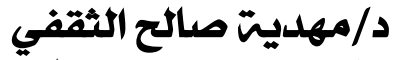

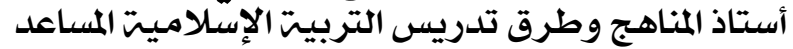

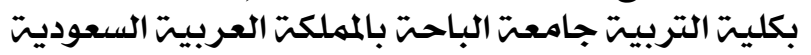





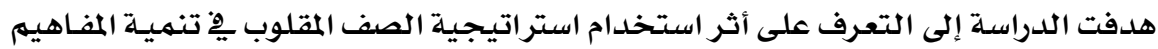

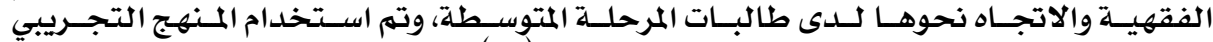

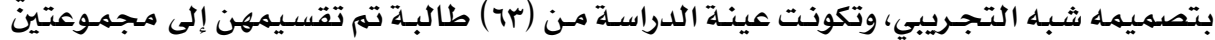

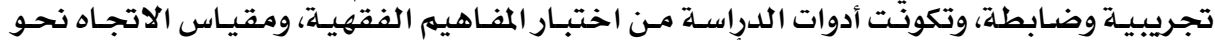

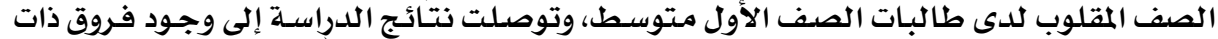

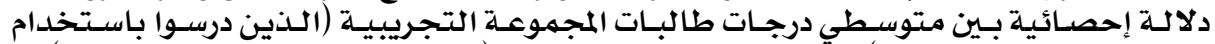

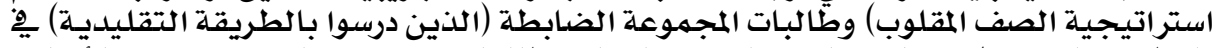

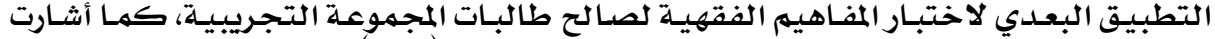

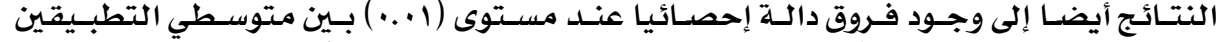

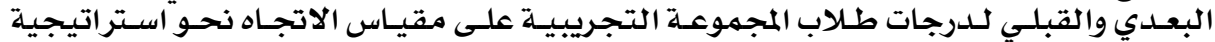

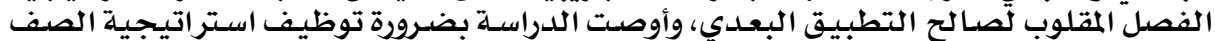

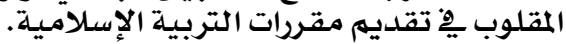
الكلمات المفتاحية: استراتيجية الصفية الصفية المقلوب - المفاهيم الفقهية - الاتجاهات.

\section{The Effect of the Flipped Classroom Strategy on Developing Fiqh} Concepts and the Attitudes Toward it Among Middle-School Female Students

\section{Abstract:}

Azza Sankour Alzahrani \& Dr. Mahdia Saleh Alsakafi

The study investigates the effect using the flipped classroom strategy on developing Fiqh concepts and the attitudes toward them among middle school female students. The instruments include a Fiqh concepts achievement test and an attitudes scale towards the flipped classroom strategy. The sample (N= 63), from the first-grade students, was divided into a control group and an experimental group. The results of the study showed that there were statistically significant differences between the means scores of the experimental group students (who studied with the flipped classroom strategy) and the control group students (who studied traditionally) in the post-test concepts in favor of the experimental group. Concerning the experimental group, the results also indicated that there were statistically significant differences at the level of $(\alpha=0.01)$ between the means scores of the pre and post-application of the attitudes scale in favor of the post-application. The research recommended the need to use the flipped classroom strategy in Islamic education courses.

.Keywords: Flipped Classroom Strategy - Fiqh Concepts - Attitudes. 


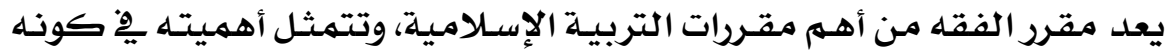

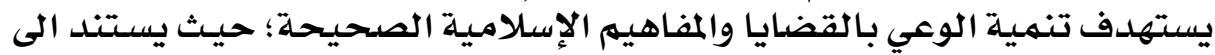

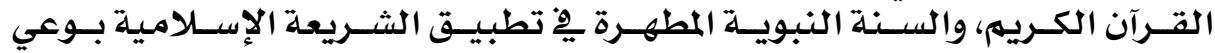

ويرتبط مقرر الفقه بأصـول الدين وأحكامـهـ لأنهيشـتهل على أحكامـا ضـابطة

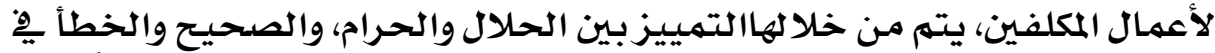

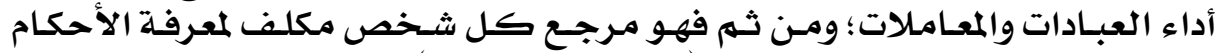

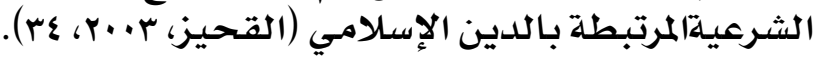

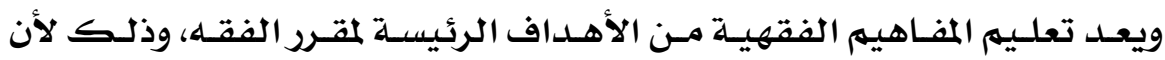

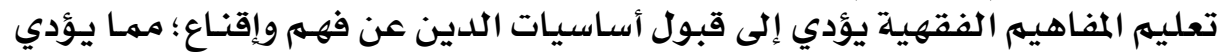

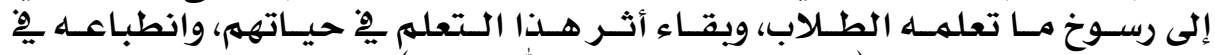

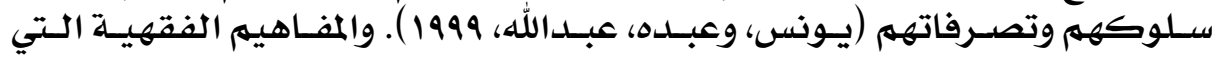

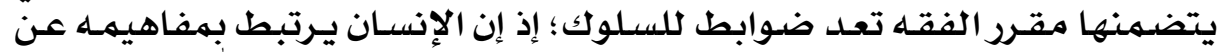

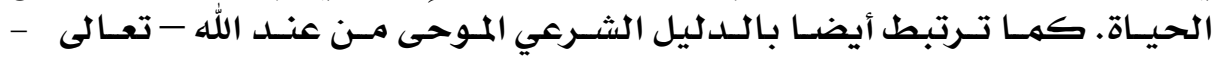

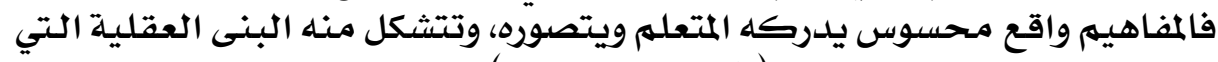

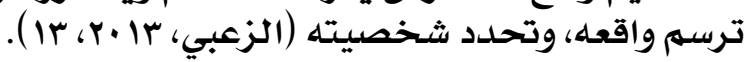

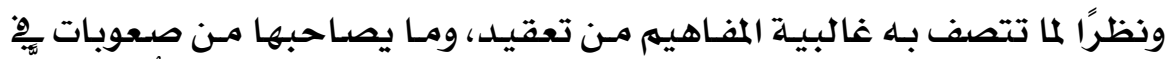

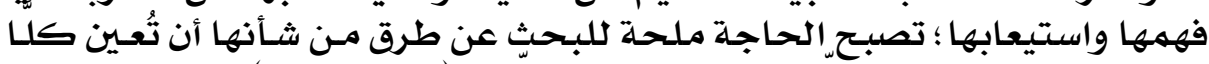

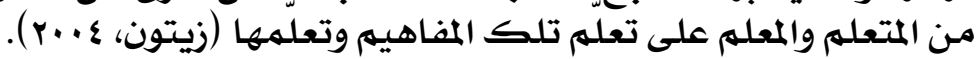

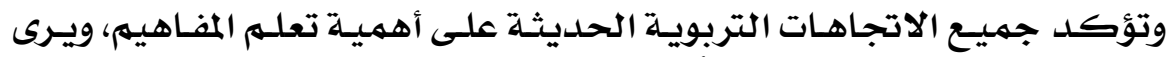

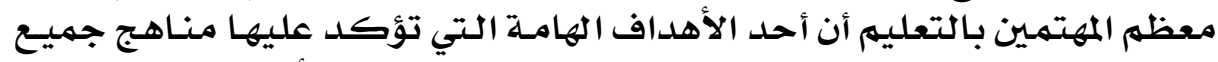

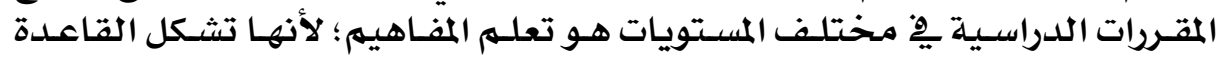

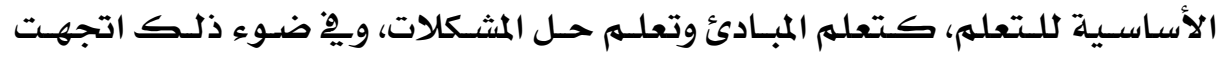
التربية الحديثة نحو استخدام " المفاهيم " فِ بناء نهاذج تعليميـة حلديثة.

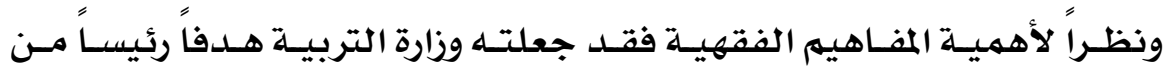

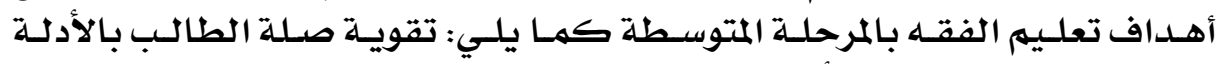

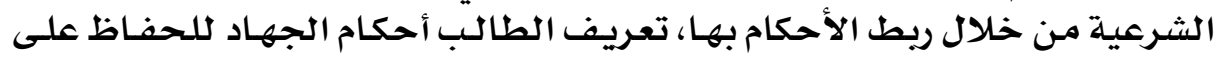

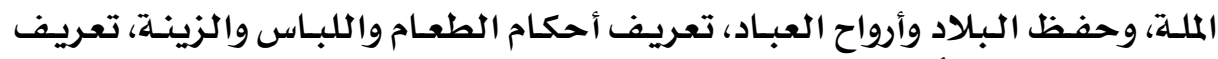

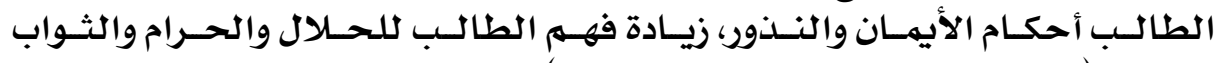

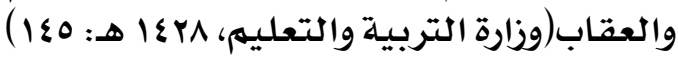

ومـع انتشار تقنيات الإنترنت والاتصالات الافتراضيـة، وظهور نظم إدارة التعلـيهم

والـتعلم الالكترونـي، اهـتم الكـثيرون بـالصـف المقلــوب (Flipped Classroom) كأحد الاتجاهات الحديثة فيخ طرق التدريس (Berrett, 2012, 34). 


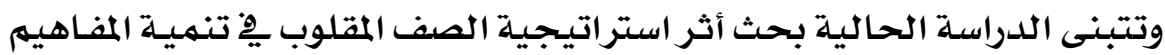
الفقهية والاتجـاه ذحو استراتيجيـة الصف المقلوب لدى طالبـات المرحلة المتوسطة.

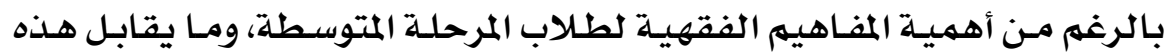

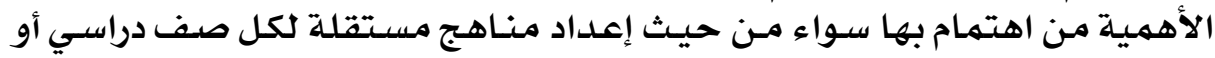

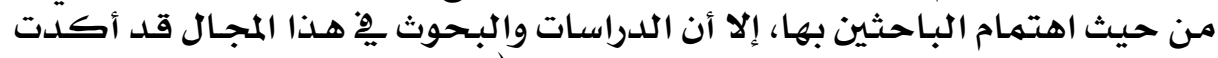

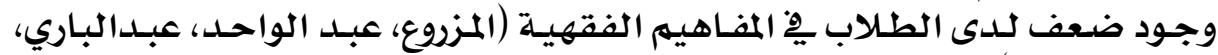

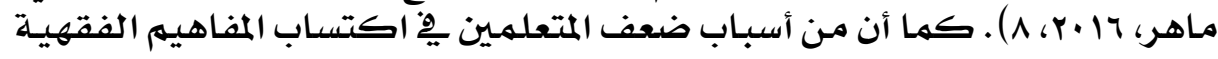

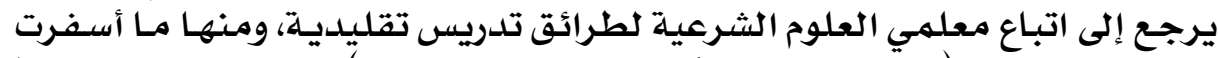

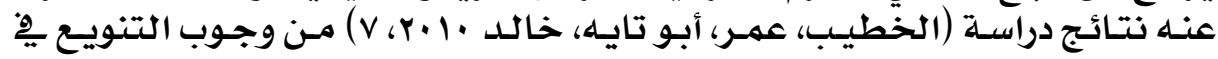

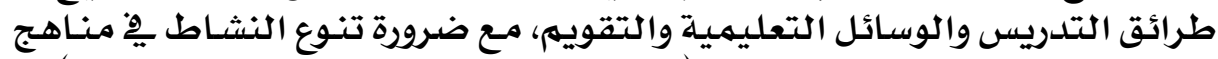

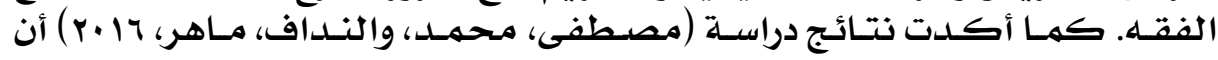

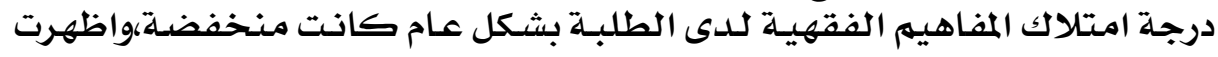

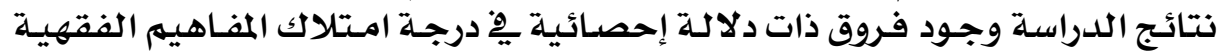

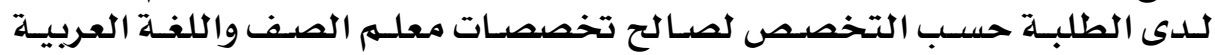

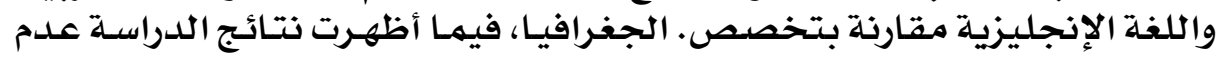

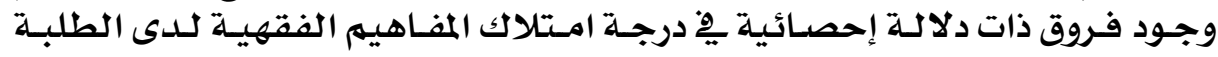

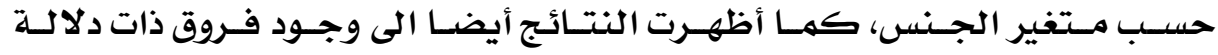

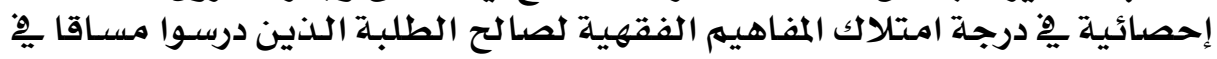

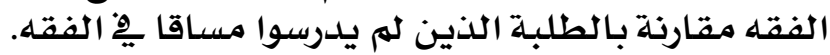

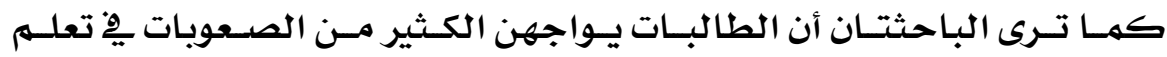

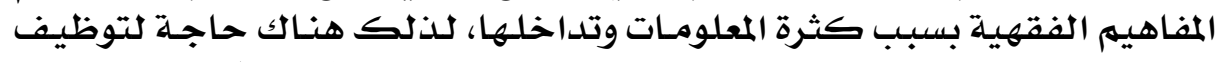

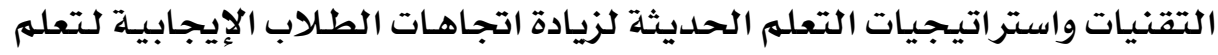

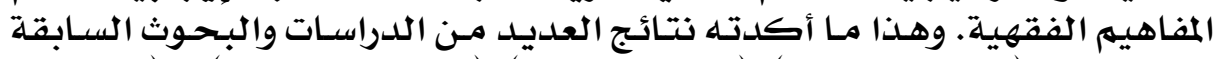

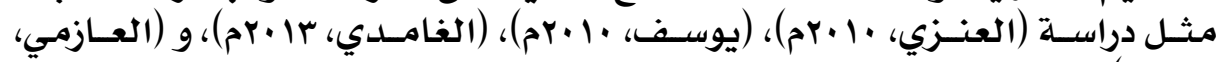

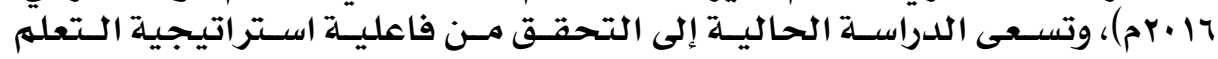

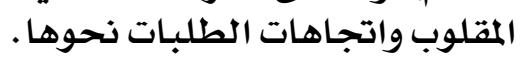

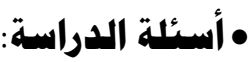

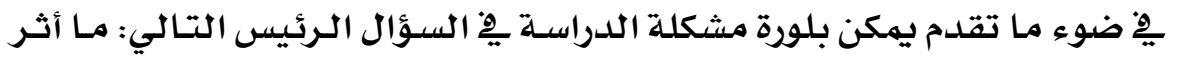

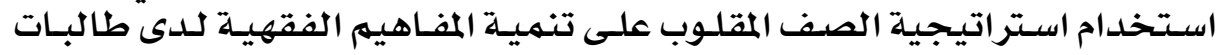

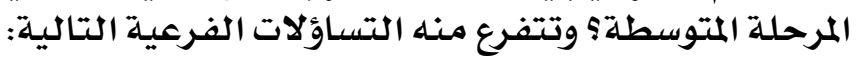

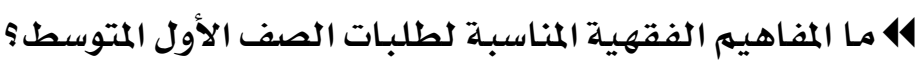

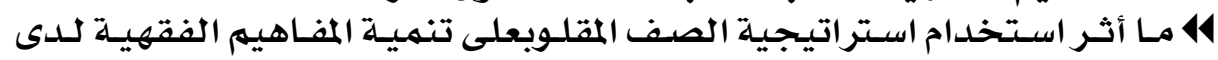

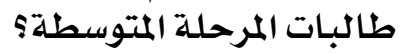

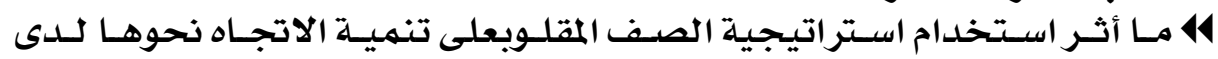

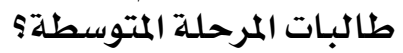




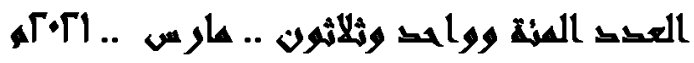

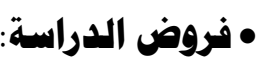
حاولت الدراسة الحالية التحقق من صحة الفروض التالية:

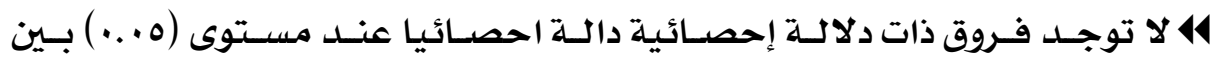

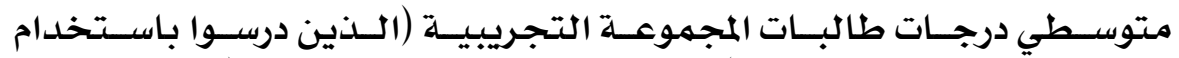

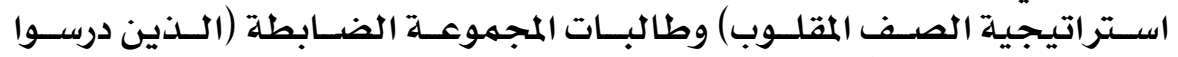

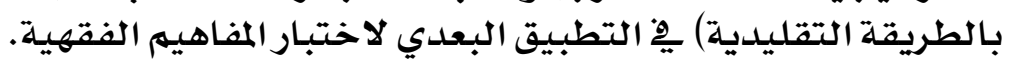

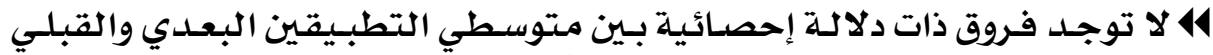

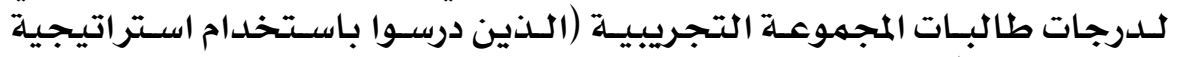

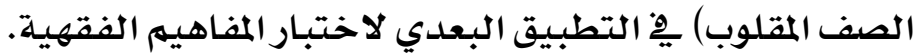

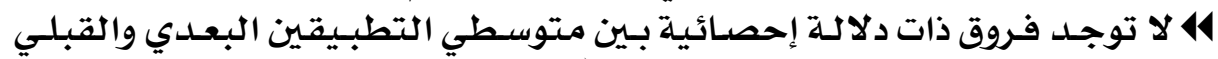

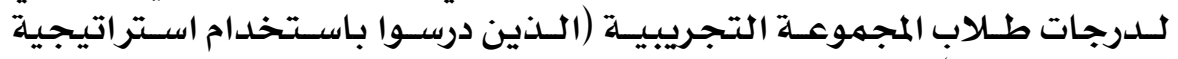

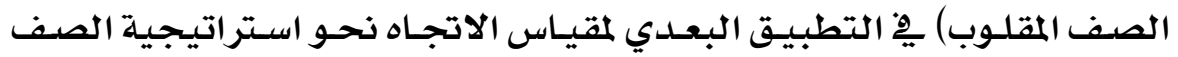

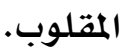

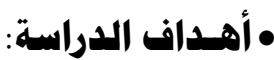

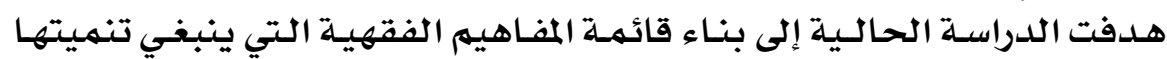

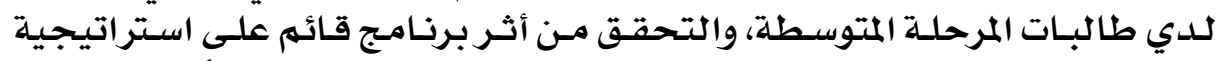

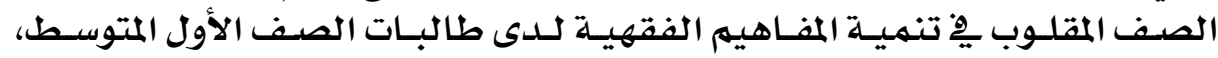

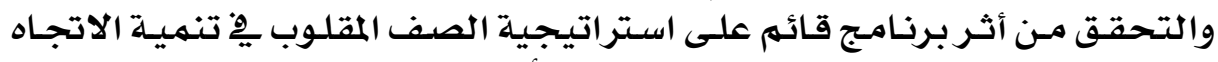
نحو استراتيجية الصف المقلوب لدى الصف الأول الترل المتوسط.

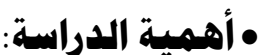

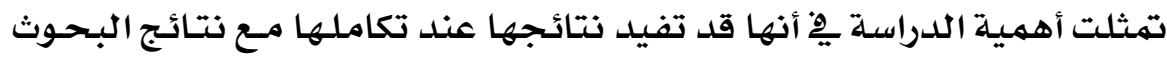

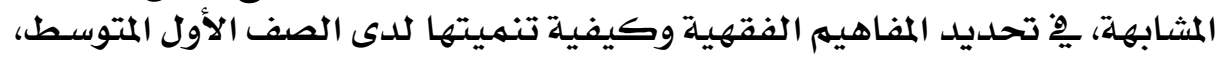

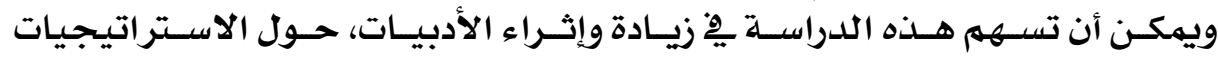

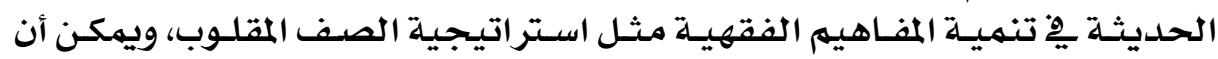
يسهم هذه الدراسة يُّ تنمية الاتجاه نحو استراتيجية الصف المقلوب. • حدود الدراسة:

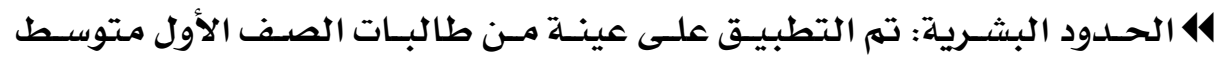

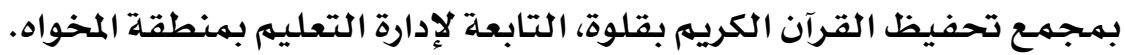

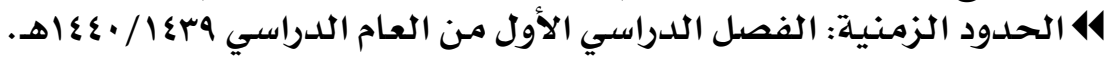

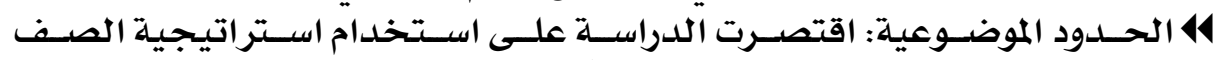

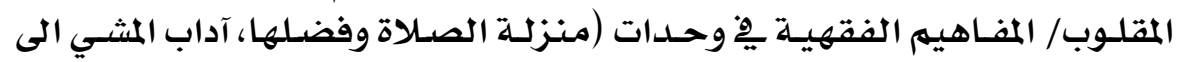

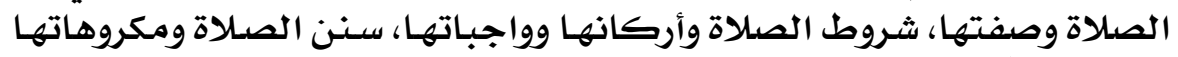
ومبطلاتها ) لطالبات الصف الأول المتوسط.

\section{IVA}


14 الصف المقلوب: وبعرف إجرائيا بأنه : أسلوب تفاعلي لتوظيف التقنيات الحديثية

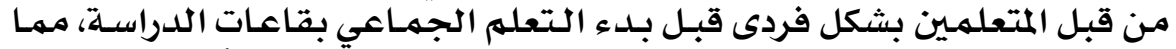

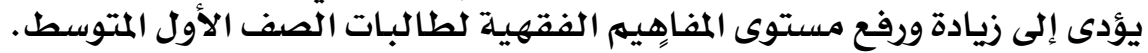

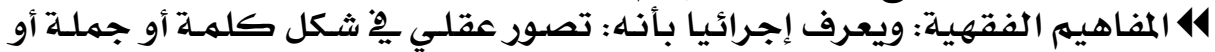

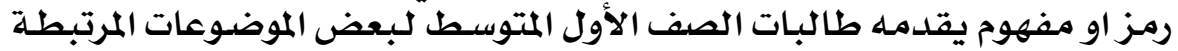

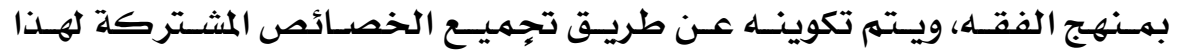

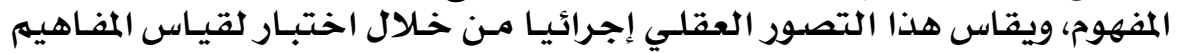

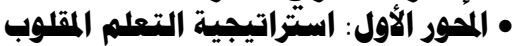

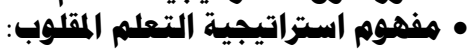

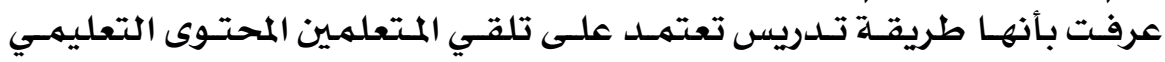

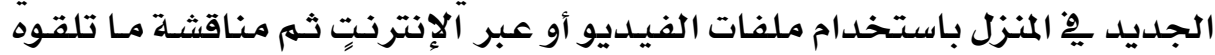

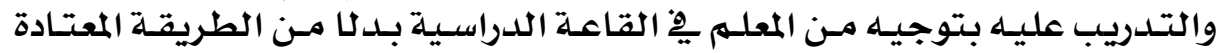

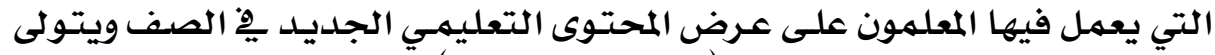

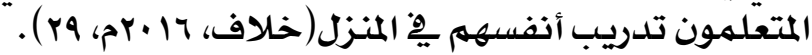

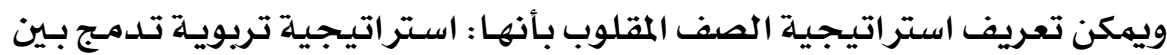

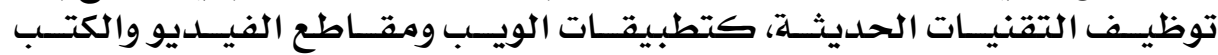

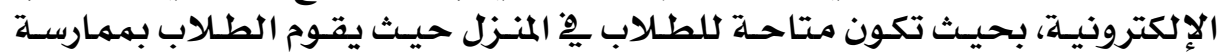

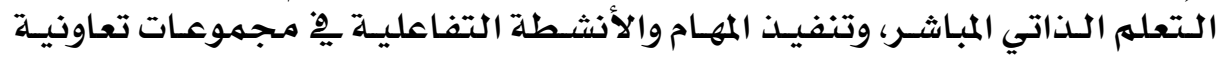

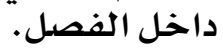

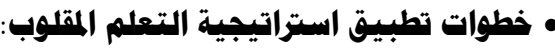

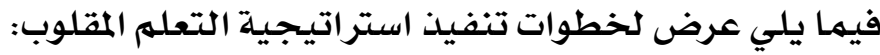

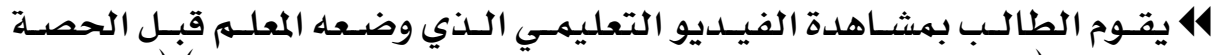

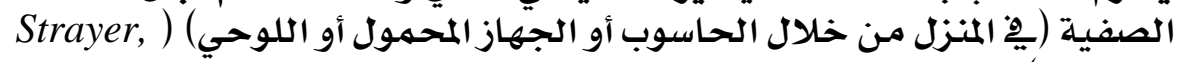
. (2007,26

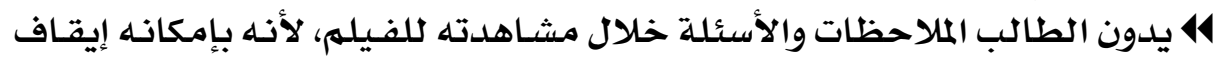

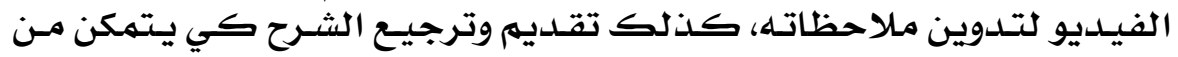

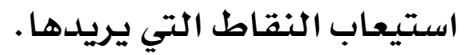

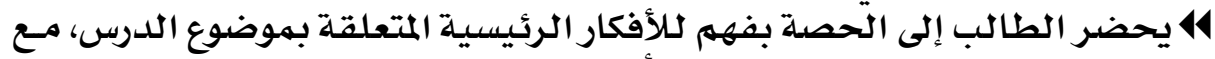

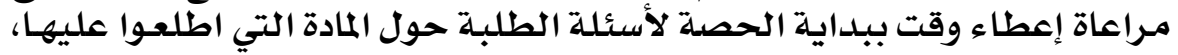

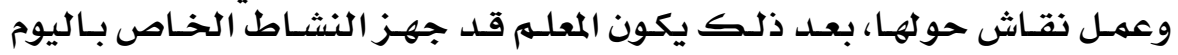

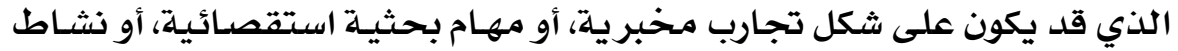

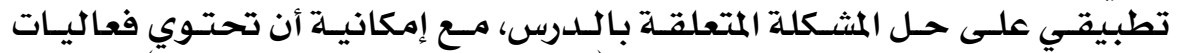

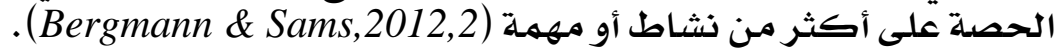




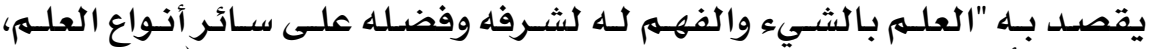

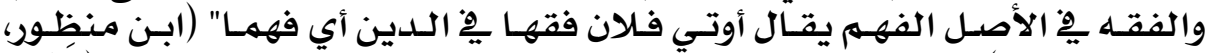

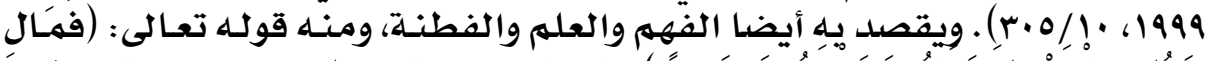

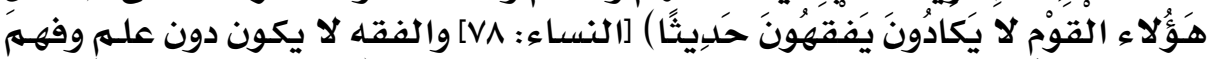

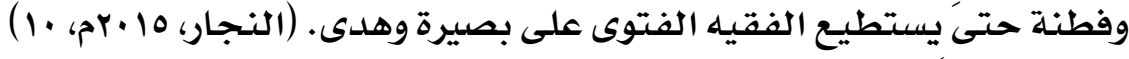
• الفقه اصطلاحا:

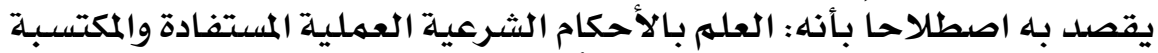

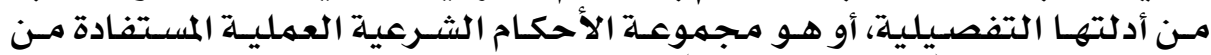

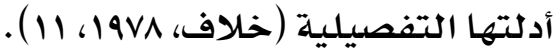

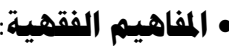

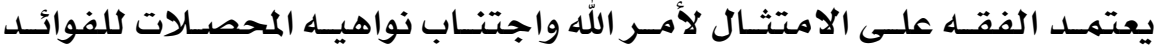

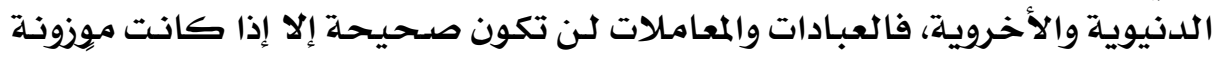

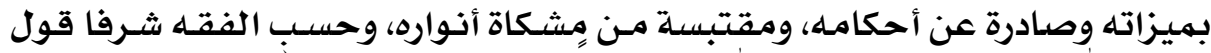

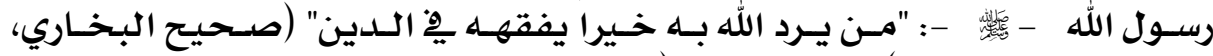

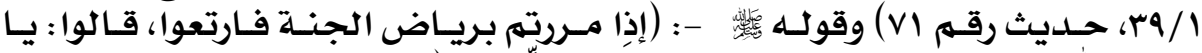

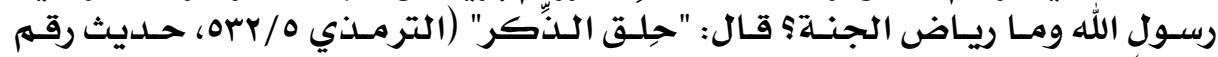
. rol.

• أقسام المفاهيم الفقهية في الفقه الإسلاهي: درج أكثر الفقهاء على تقسيهم المفاهيم الفيمي الفقهية إلى قسمـين:

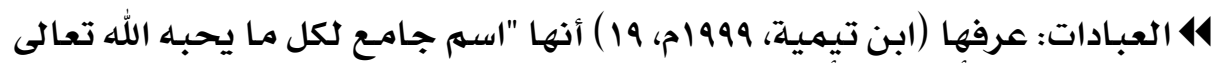

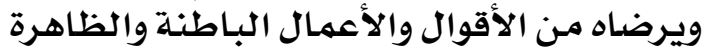

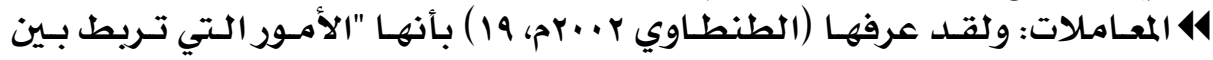

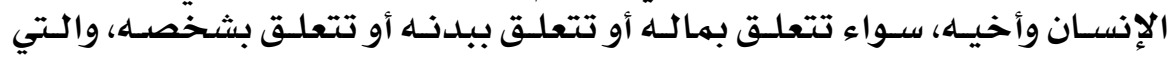

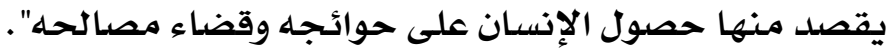

\section{• أهمية تدريس المفاهيم الفقهية:}

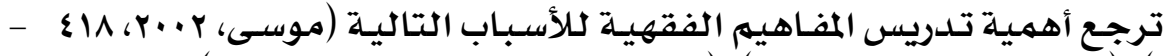

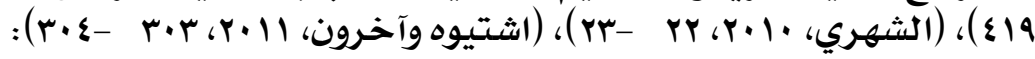

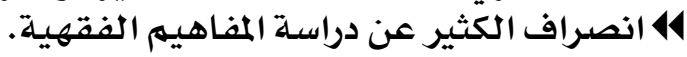

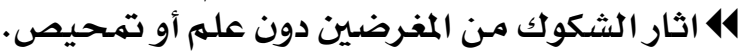

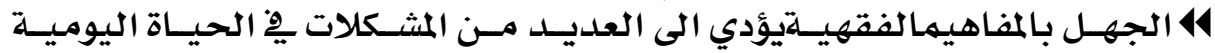

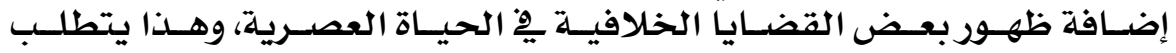

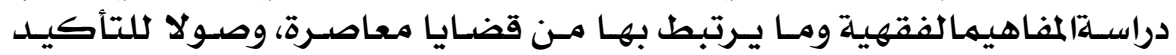

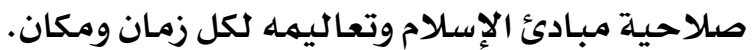

\section{$1 \wedge$.}




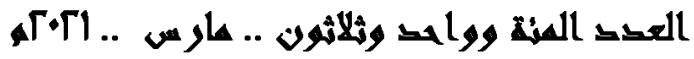

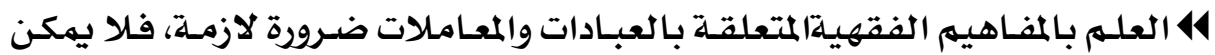

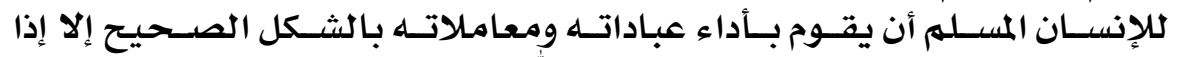

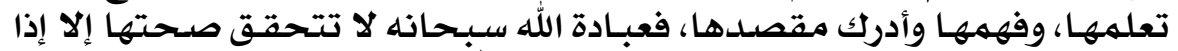

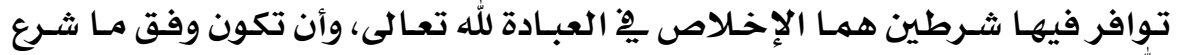

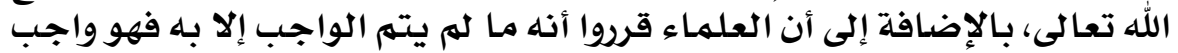

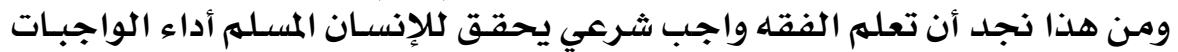

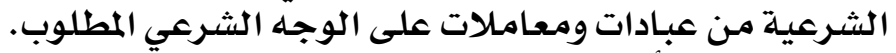

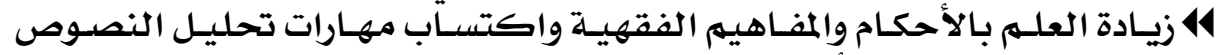

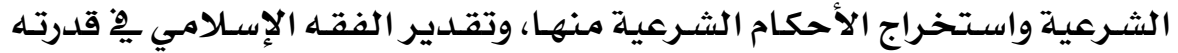
على حل قضايا الإنسان.

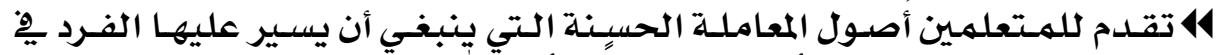

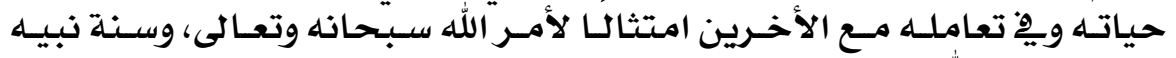
محمدل صلي الله عليه وسله وسله فيله.

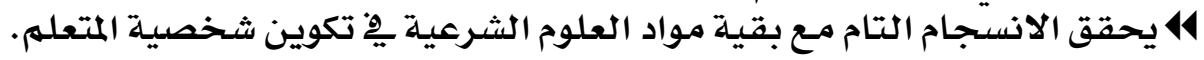

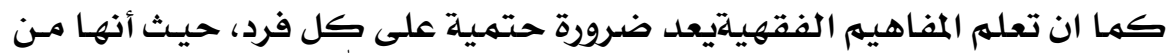

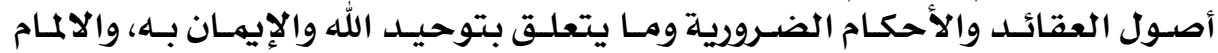

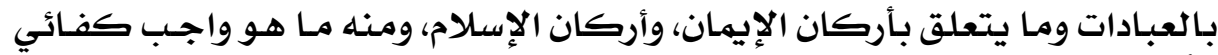

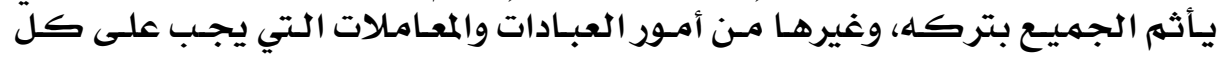

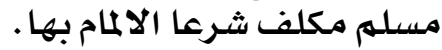

\section{• تدريس المفاهييم الفقهية للهرحلة المتوسطة في المهلكة:}

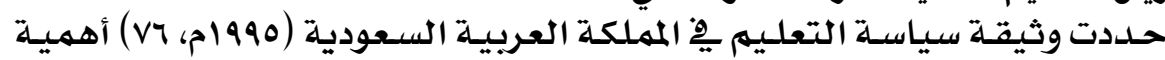

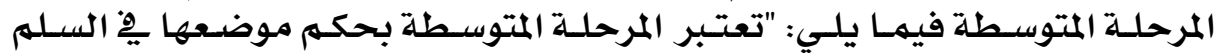

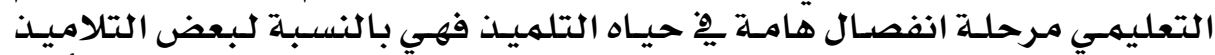

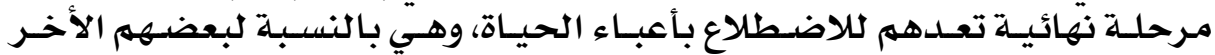

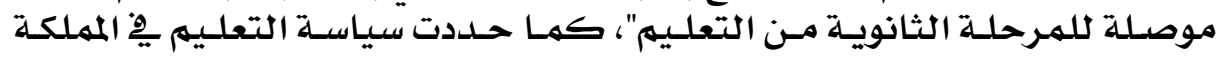

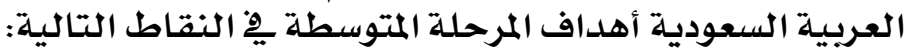

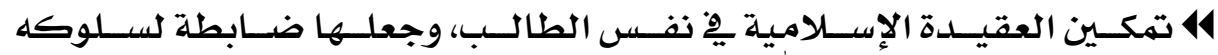

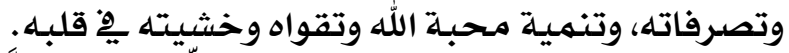

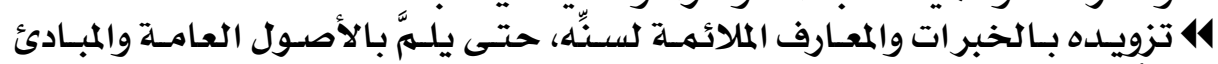

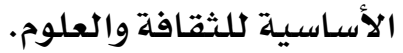

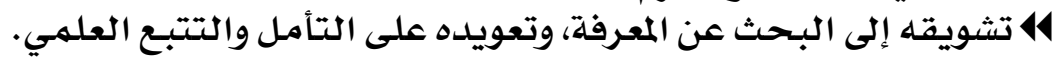

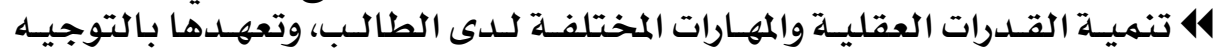
والتهذيب.

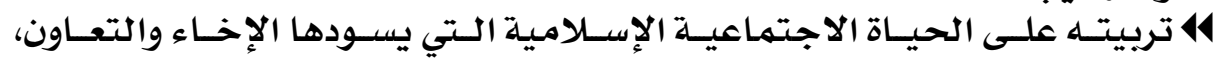

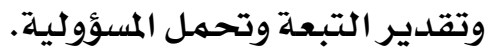

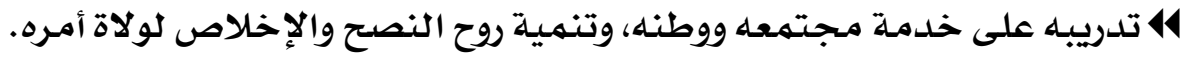

\section{$1 \wedge 1$}




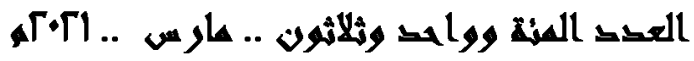

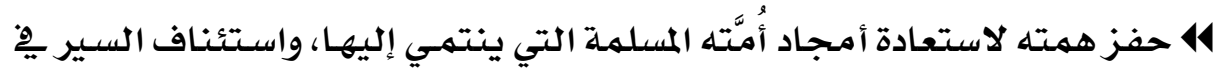
طريق العزة والمجد.

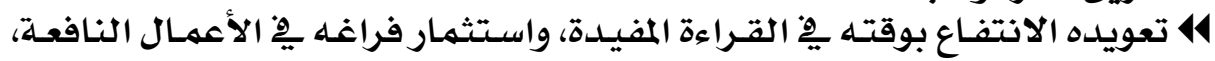

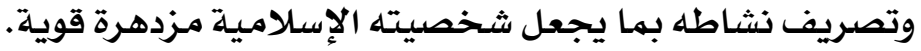

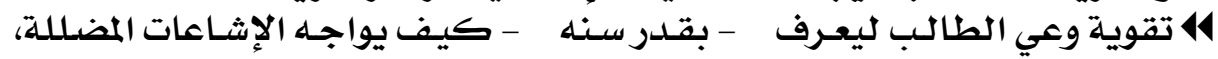
والمذاهب التهدامة، والمبلمبادئ الدخيلة الميلة.

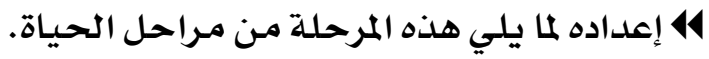

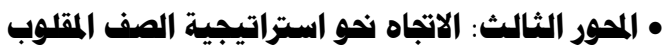

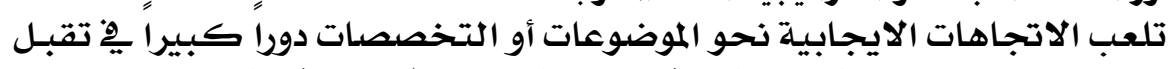

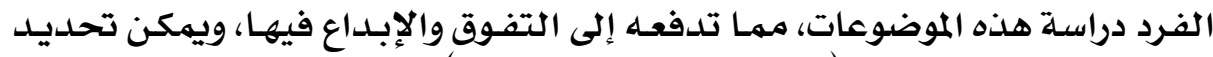

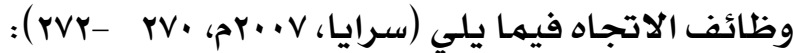

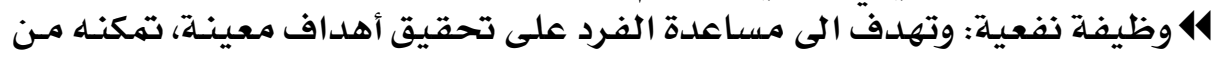

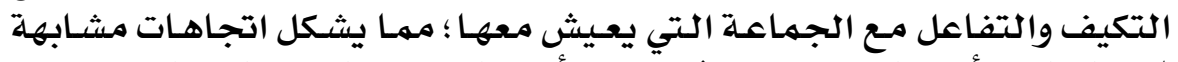

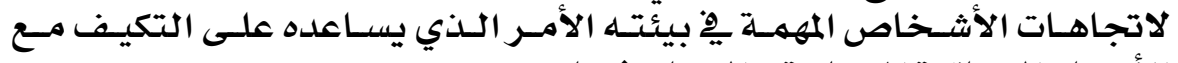
الأوضاع الحياتية المختلفة، والنجات النجاح فيها.

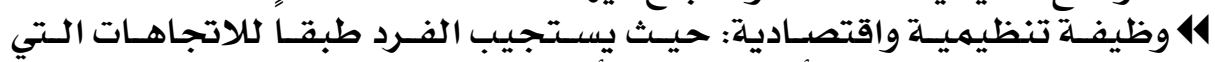

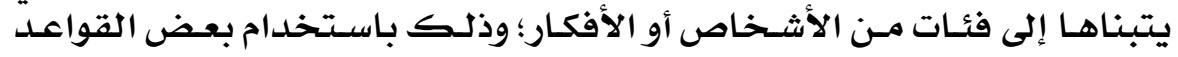

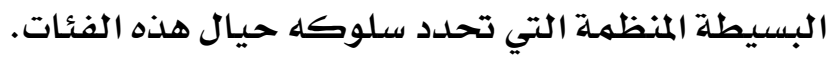

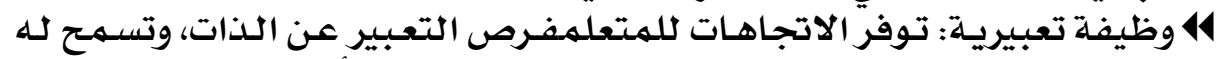

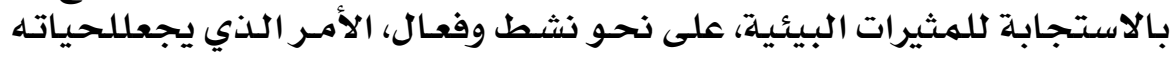

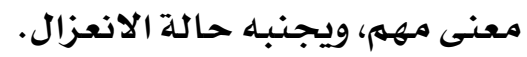

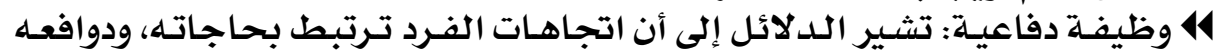

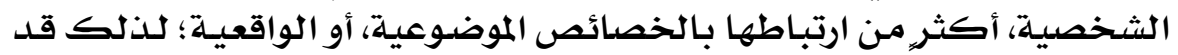

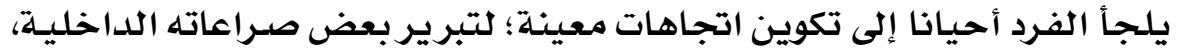

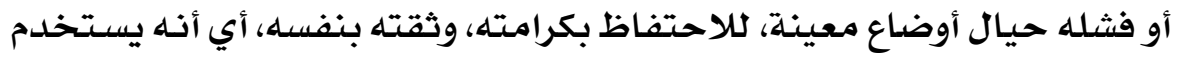

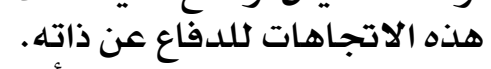

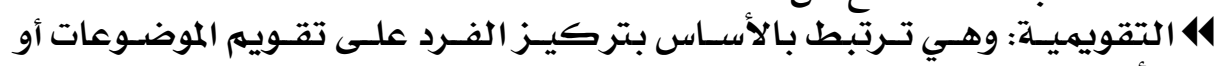

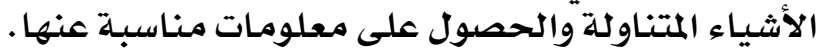

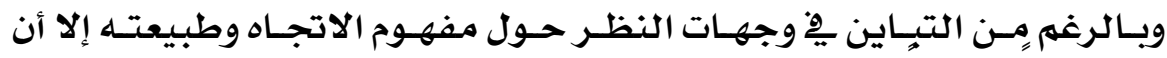

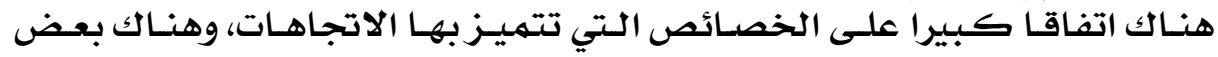

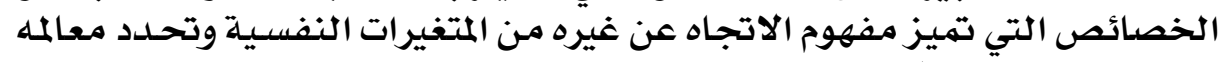

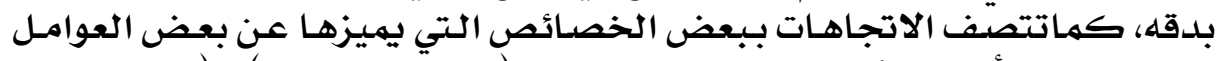

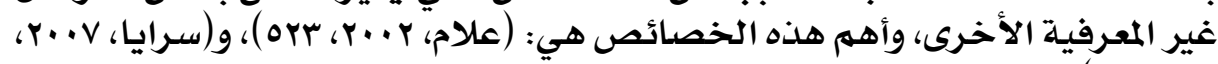
(rTV:rTt

ل4 الاتجاهـات متعلمـة أي أنها ليست غريزيـة، أو فطريـة موروثة؛ بـل أنها متعلمهـة

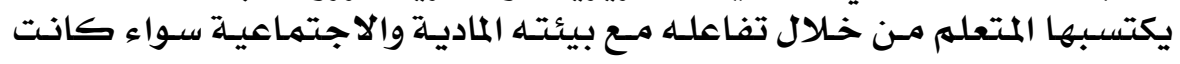

\section{$1 \wedge Y$}

دراسات عربية في التربية وعلم النفس (ASEP) 


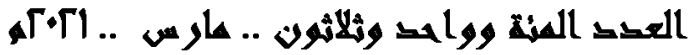

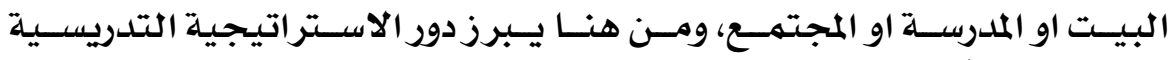

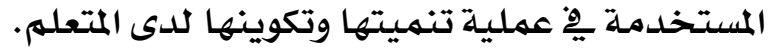

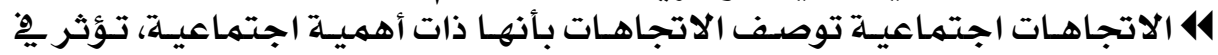
علاقة المتعلم بزملاتئه والعكس.

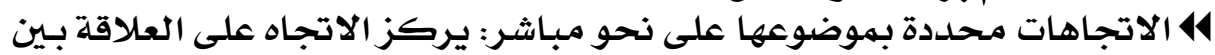

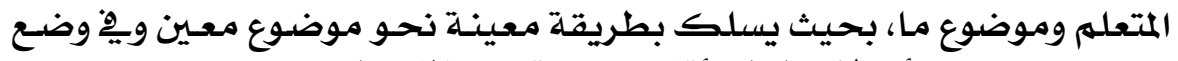

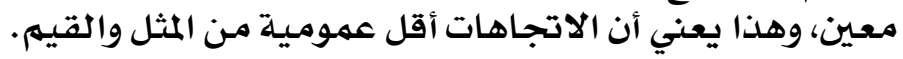

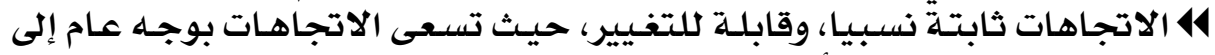

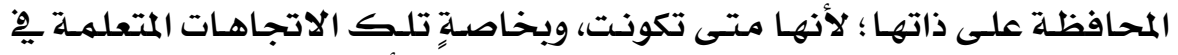

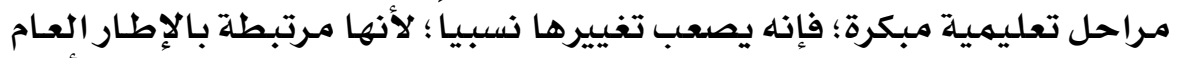

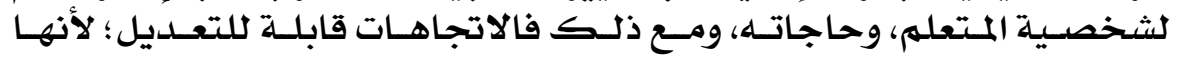

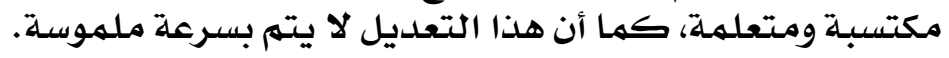

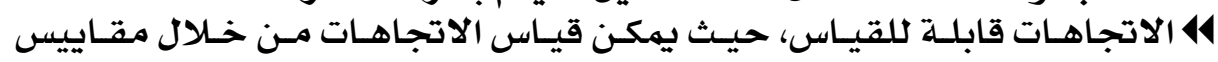

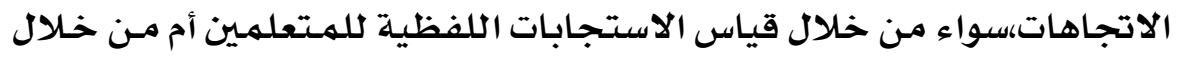
قياس الاستجابات الملاحظة لهمه.

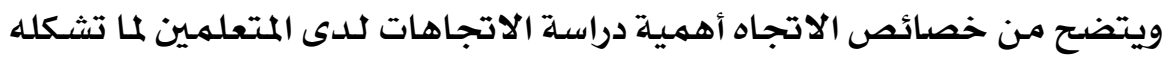

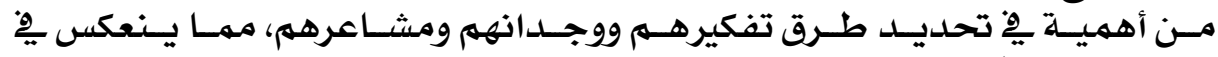

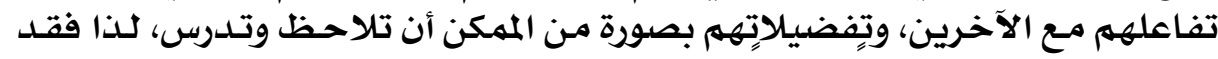
لاقت الاتجاهات اهتماما كبيرا من الباحثين.

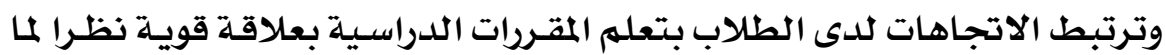

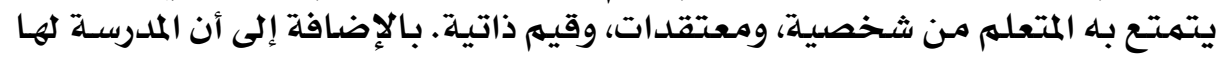

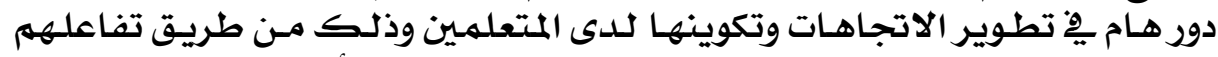

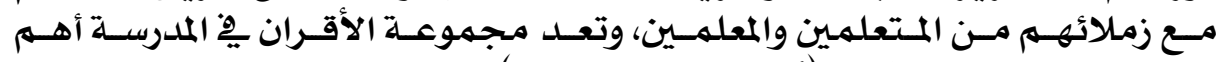

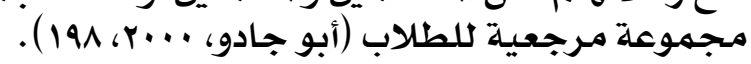

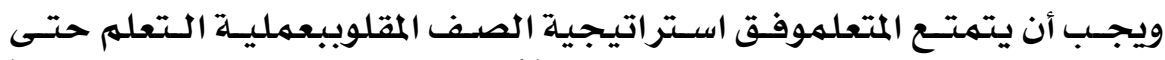

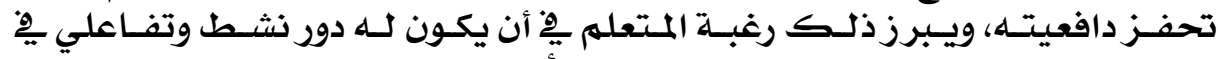

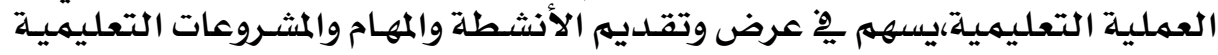

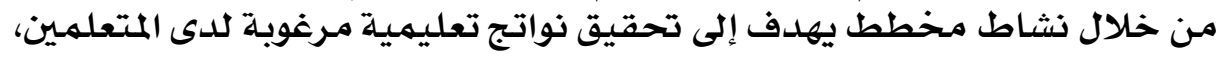

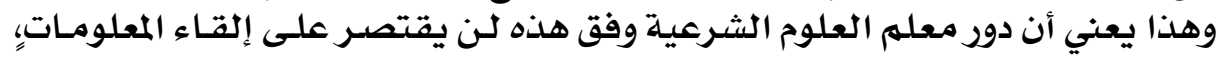

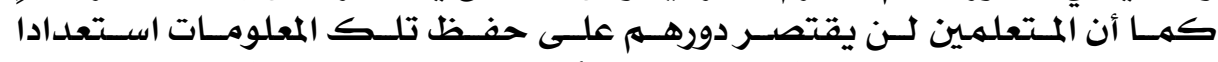

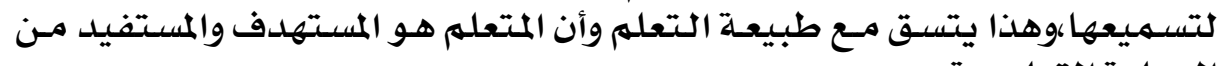

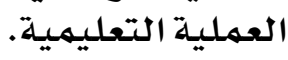

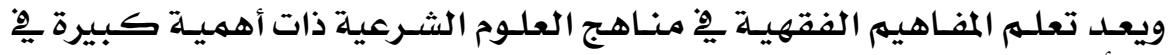

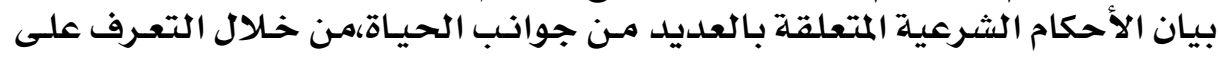

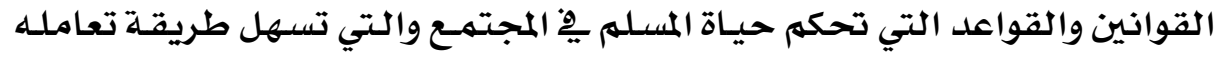




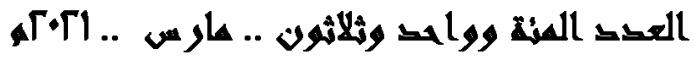

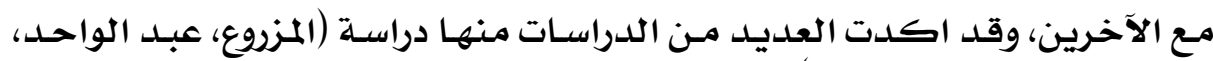

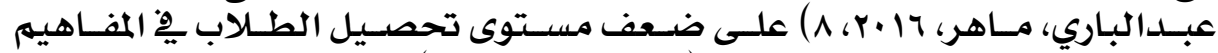

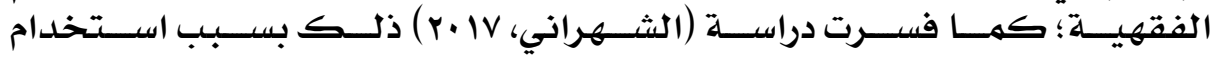

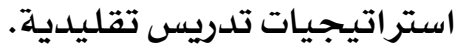

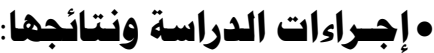 • منهج الدراسة ومتغيراتها:}

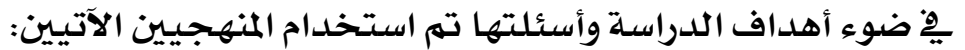

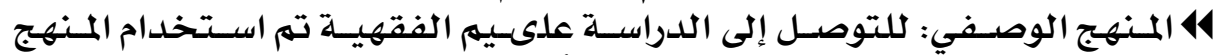

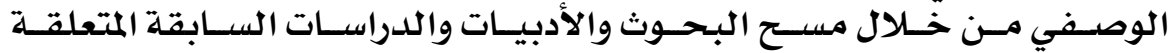

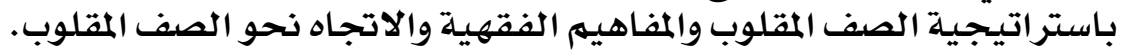

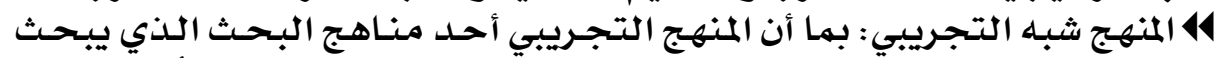

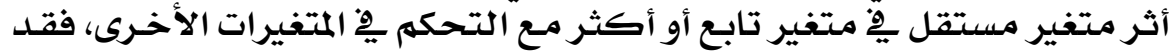

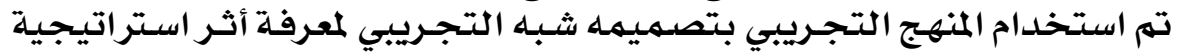

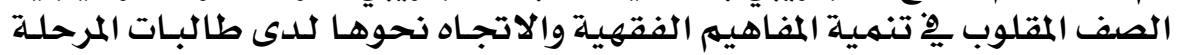
المتوسطة.

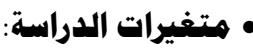

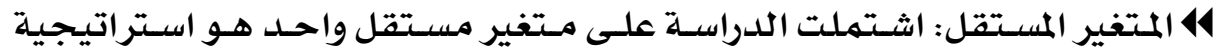

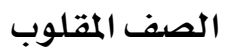

14 المتغيرات التابعة: اشتملت الدفوراسـة على متغيرين تابعين هما :

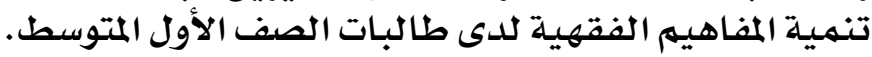

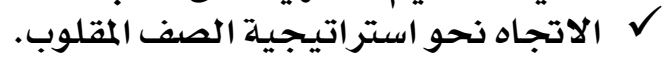

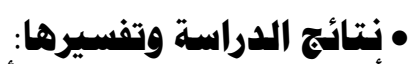

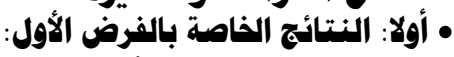

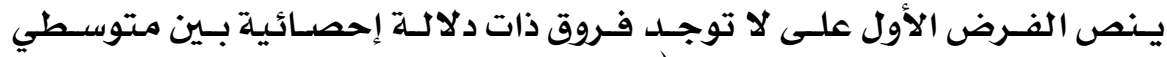

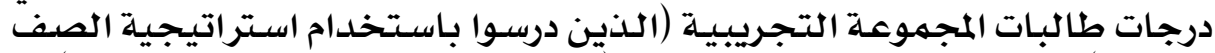

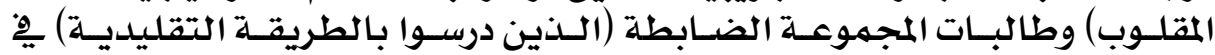

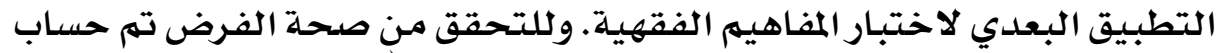

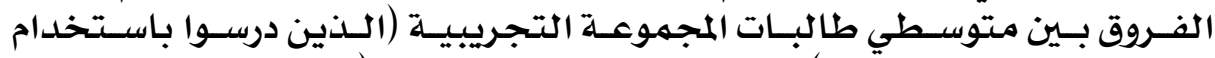

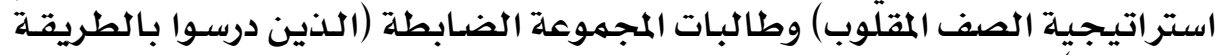

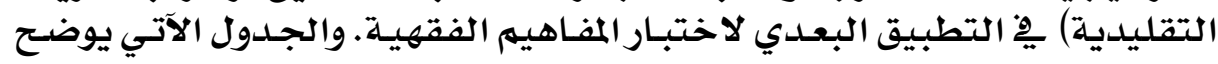

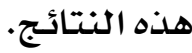

جدول (1) نتائج اختبار ت للفرق بين متوسطي المجموعتين التجريبيت والضابطت بـ القياس البعدي لاحتبار المفاهيم الفمقهيت

\begin{tabular}{|c|c|c|c|c|c|c|}
\hline الدلالة & |درجت الحريت | & ت المحسوبت & |الانحراف المعياري & المتوسط & العلدد & المجموعات \\
\hline \multirow[b]{2}{*}{ لت عند مستوى اب. } & \multirow[b]{2}{*}{$T r$} & \multirow[b]{2}{*}{ re.ro } & 4.88000 & 89.5758 & 33 & بطت \\
\hline & & & 1.33357 & 121.1818 & 31 & ريبيت \\
\hline
\end{tabular}

\section{$1 \wedge \varepsilon$}




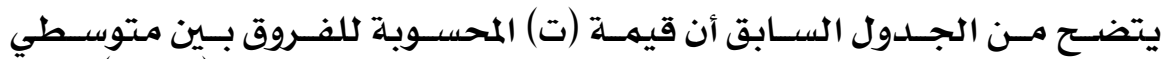

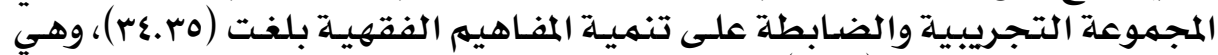

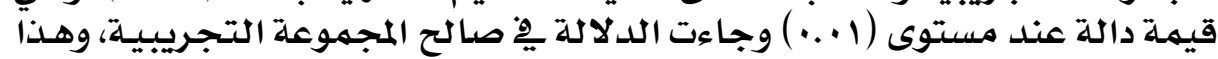

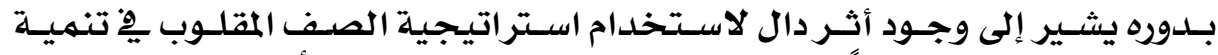

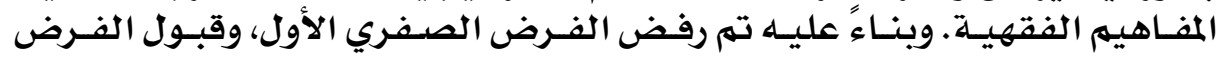

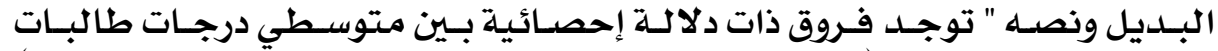

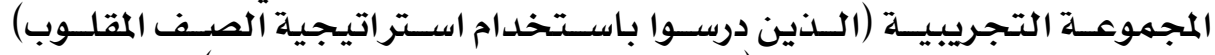

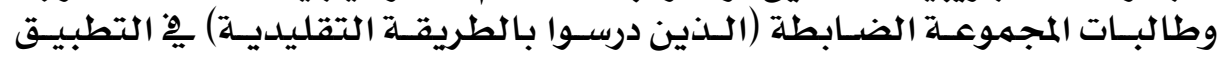

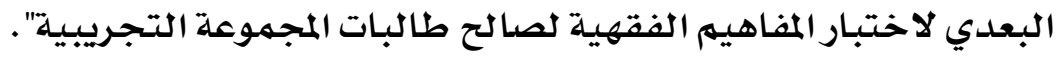

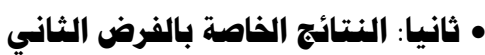

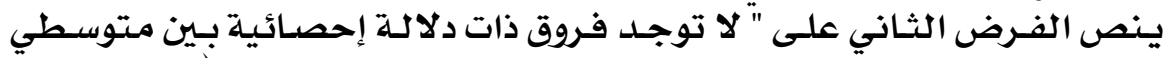

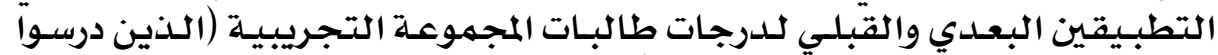

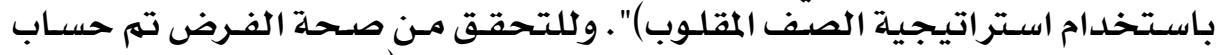

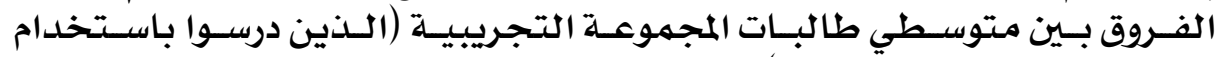

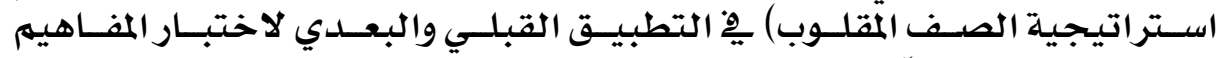

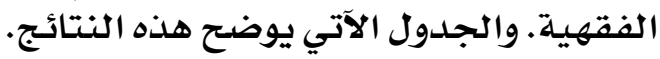

جدول (r) نتائج اختبار ت للفرق بين متوسطي التطبيقين القبلي والبعلدي لاختبار المفاهيم الفقهيت

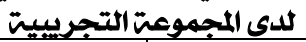

\begin{tabular}{|c|c|c|c|c|c|}
\hline الدلالت & |رجت الحريت & ت المحسويت & الانحراف المعياري & المتوسط & \\
\hline لت عند مستوي اب. & rY & rr.q1 & 3.96863 & 17.0000 & \\
\hline & TI & Tr. 91 & 4.02149 & 47.8788 & \\
\hline
\end{tabular}

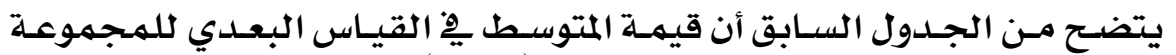

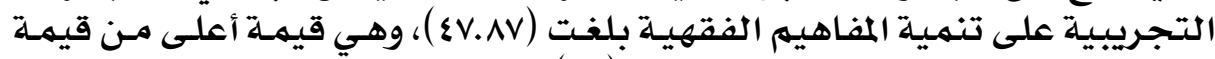

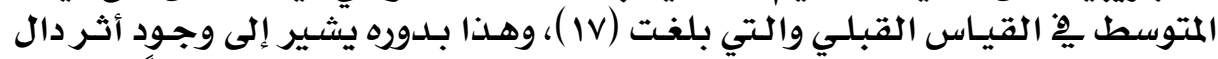

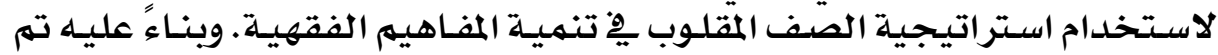

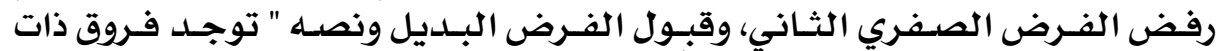

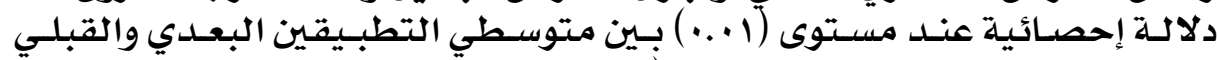

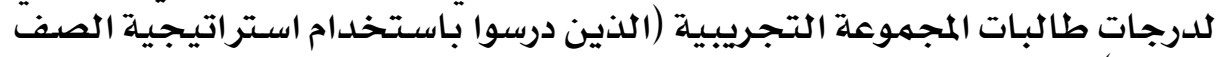

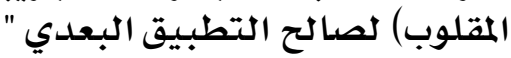

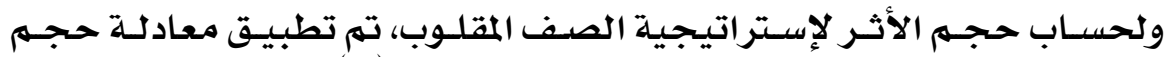

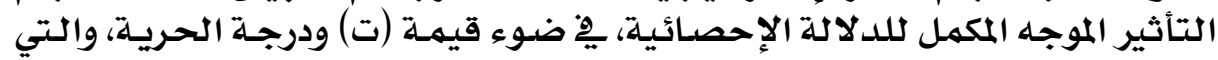

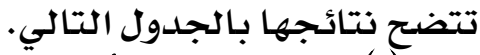

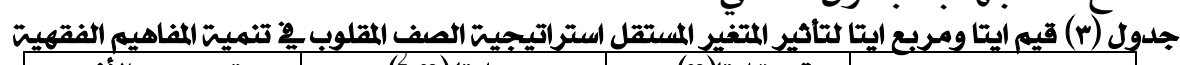

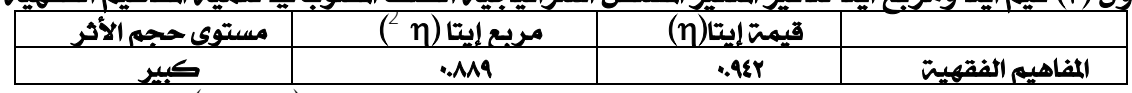

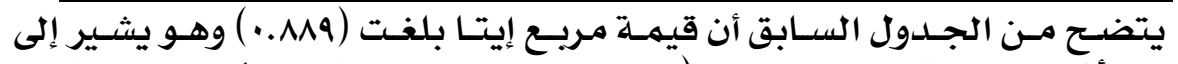

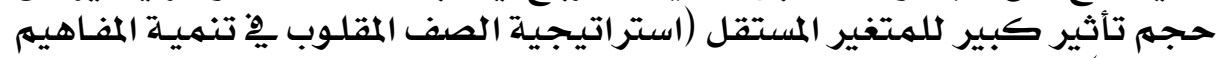

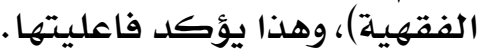




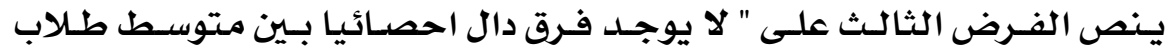

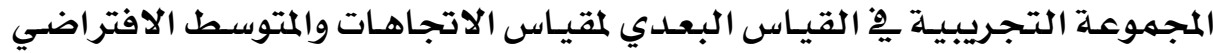

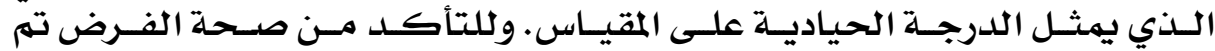

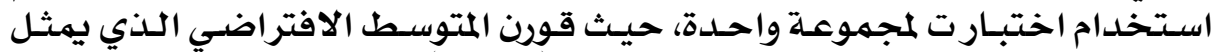

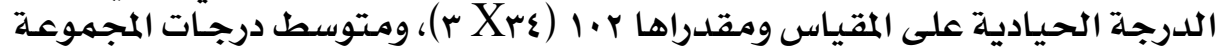

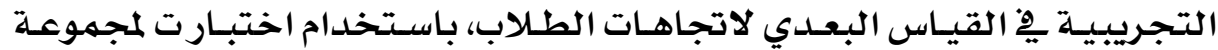

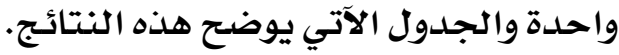

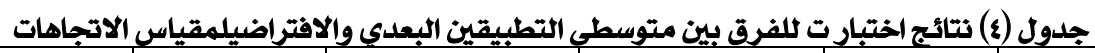

\begin{tabular}{|c|c|c|c|c|c|}
\hline الدلالة & |درجت الحريت & ت المحسوبت & الانحراف المعياري & المتوسط & المتوسط \\
\hline \multirow{2}{*}{ كت همد مستوى اب.. } & \multirow{2}{*}{$r r$} & \multirow{2}{*}{ AY.Tr } & 1.rr & $1 r \mid .11$ & بعدي \\
\hline & & & - & 1.r & افتراضى \\
\hline
\end{tabular}

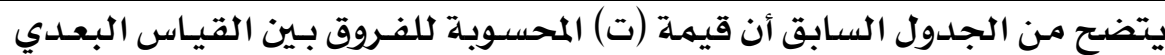

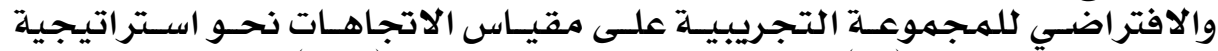

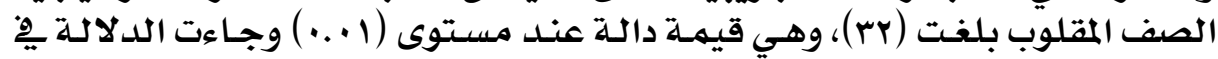

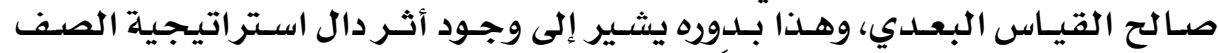

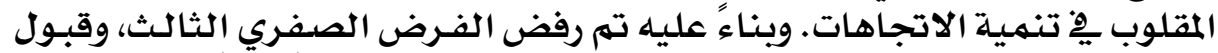

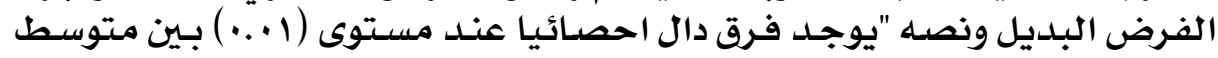

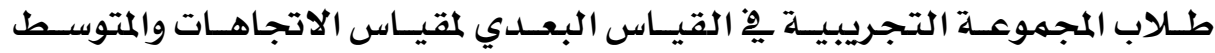

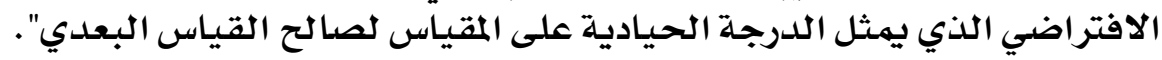

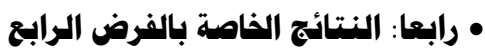

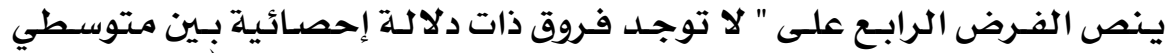

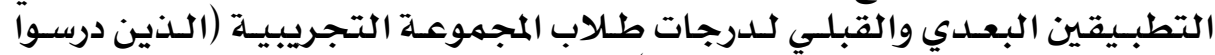

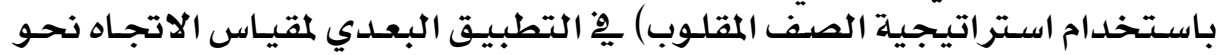

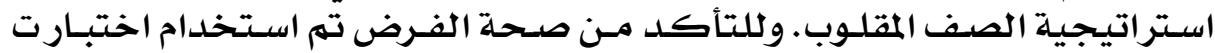

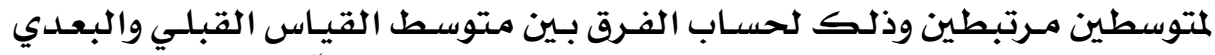

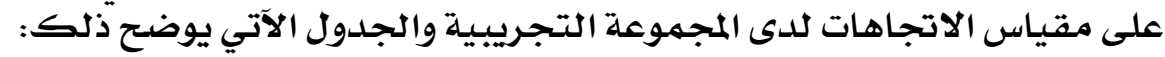

جدول (ه) نتائج اختبار تلفرق بين متوسطي القياس القبلي والبعدي لمقياس الاتجاهات للى المجموعت

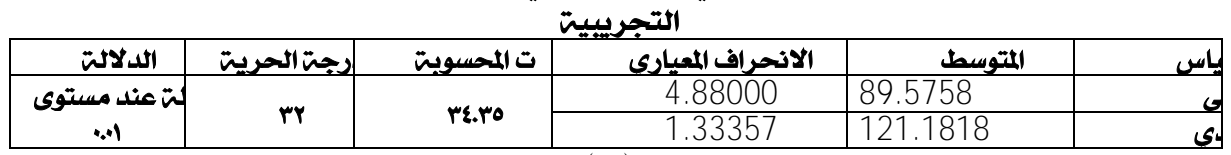

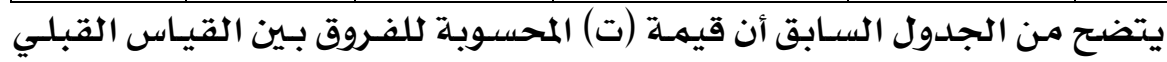

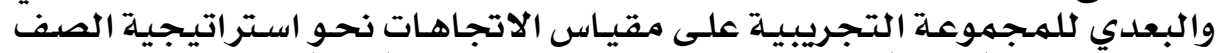

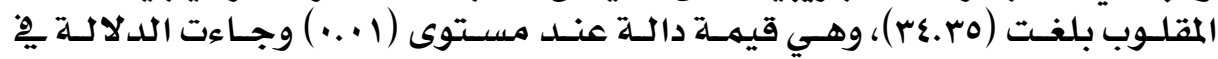

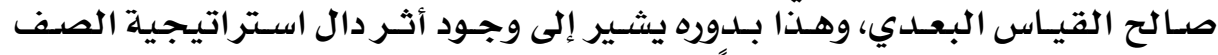

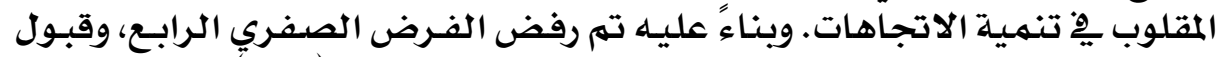

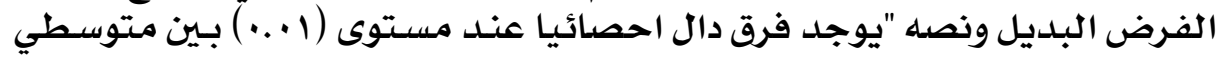




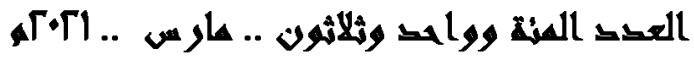

التطبـيقين البعـدي والقبلـي لـدرجات طلاب المجموعـة التجريبيـة (الـذين درسـوا

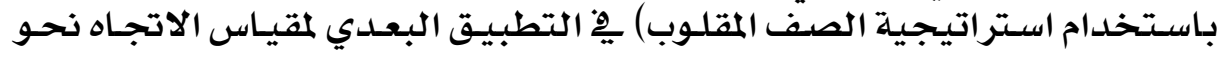
استراتيـجية الصف المقلوب لصاتجراتح القياس البعلدي".

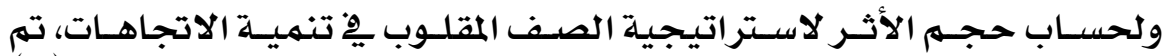

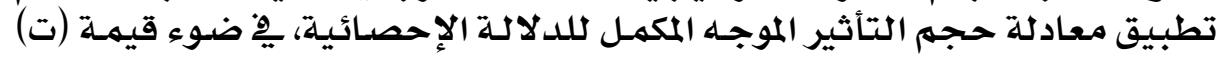

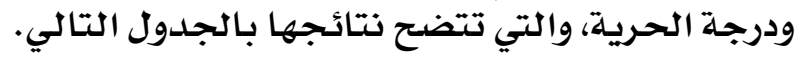

جلدول (7) قيم ايتا ومربع ايتا لتاثير المتغير المستقل استراتيجيت الصف المقلوب مِ تنميت الاتجاهات

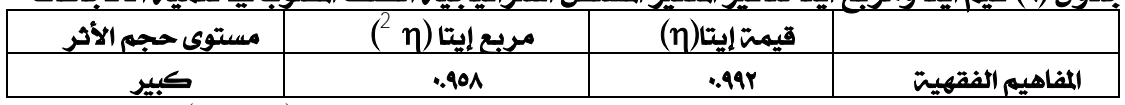

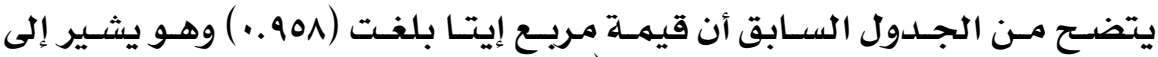

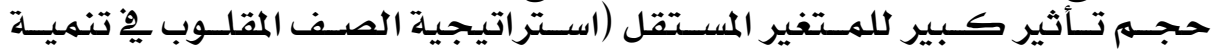
الاتجاهات)، وهذا يؤكس تهد فاعليتها .

\section{• هناقشة وتفسير النتائج:

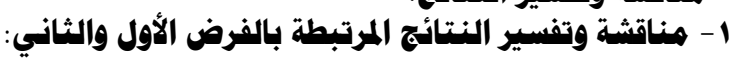

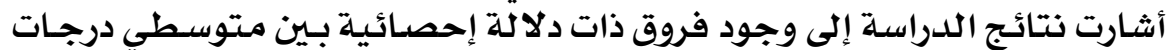

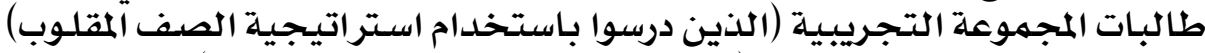

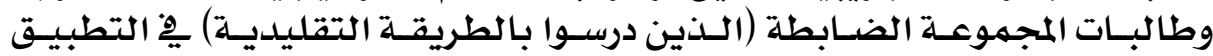

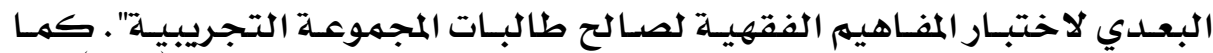

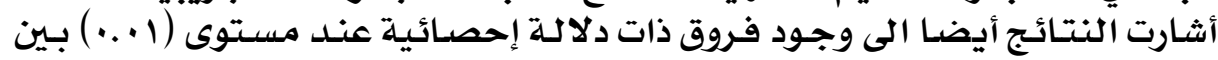

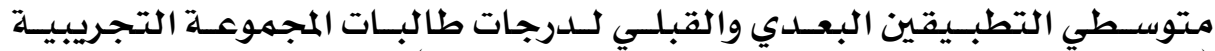

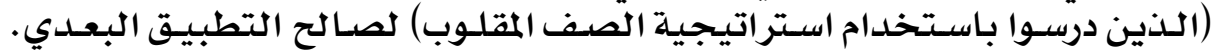

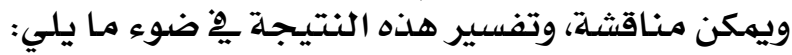

1أن دراسـة الطالبـات من خلال استراتيـجية الصف المقلوب قد زودتهن بـالكثير مـن

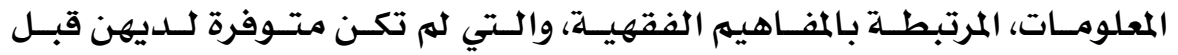

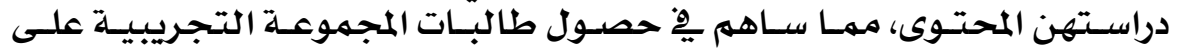

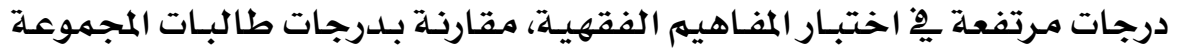
الضنابطة.

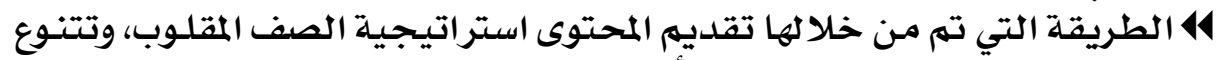

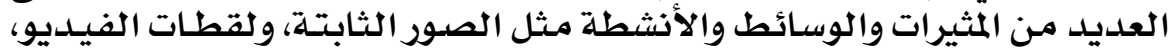

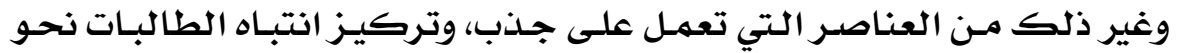

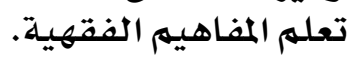

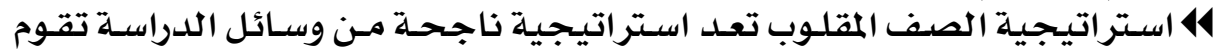

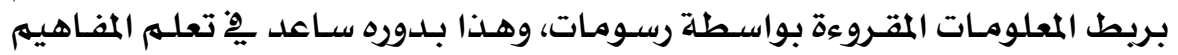
الفقهية.

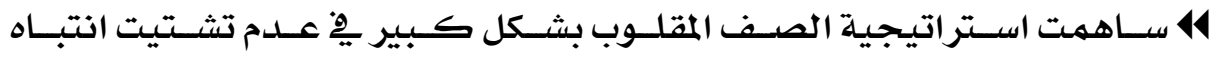

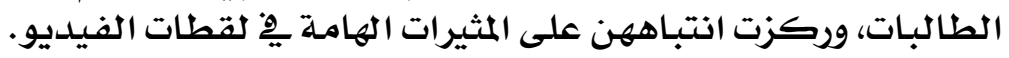




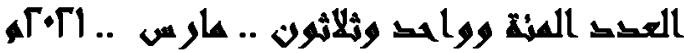

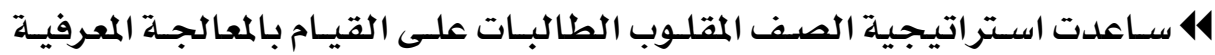

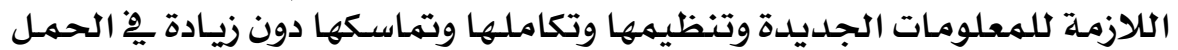

المعربِ.

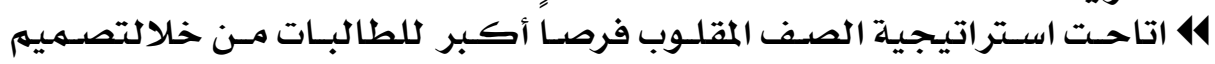

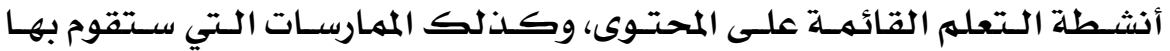
الطالبات.

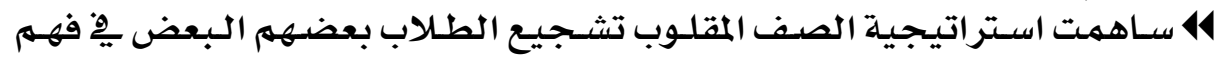

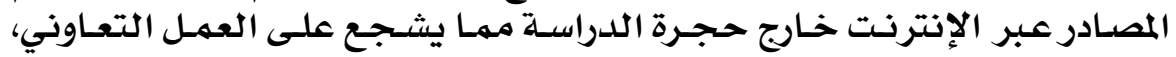

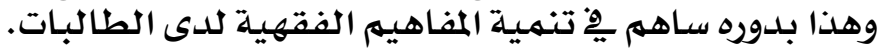

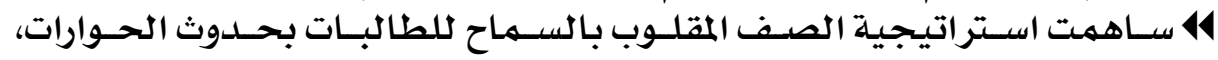

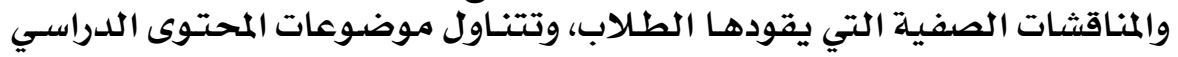

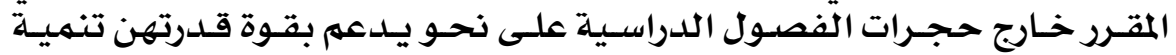
المفاهيم الفقروحية.

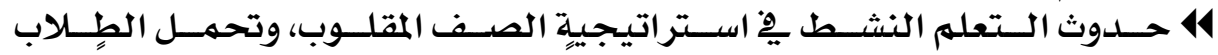

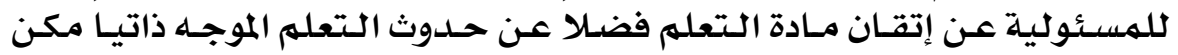

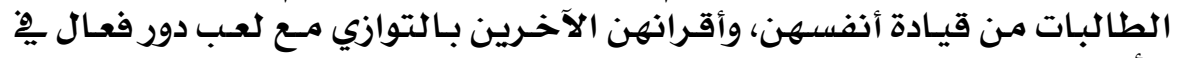

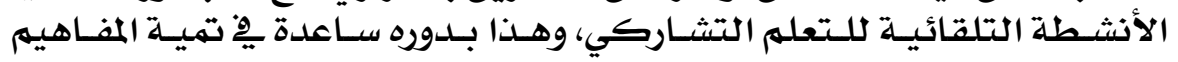
الفقهية.

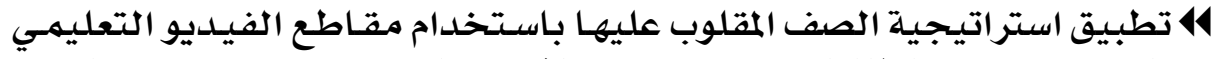

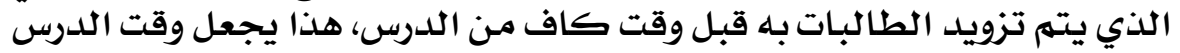

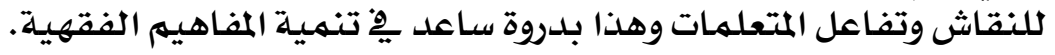

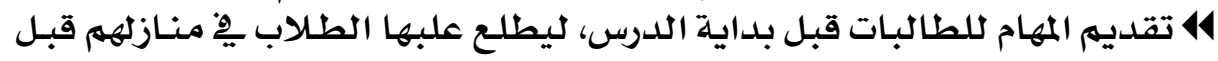

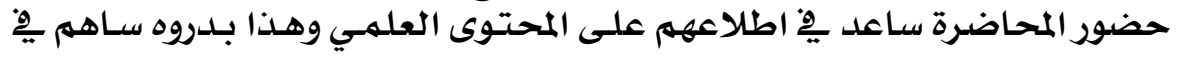

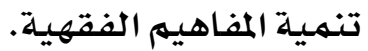

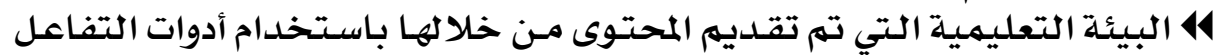

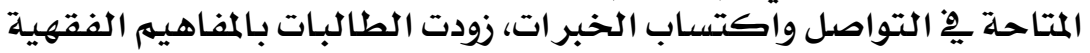

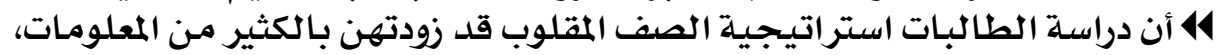

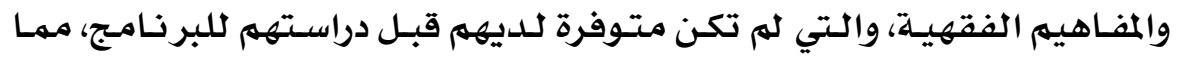

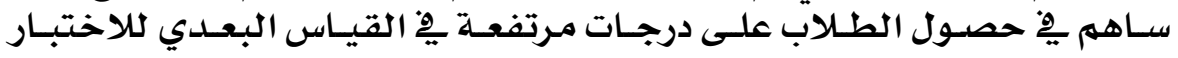

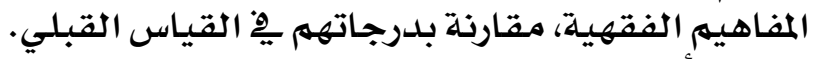

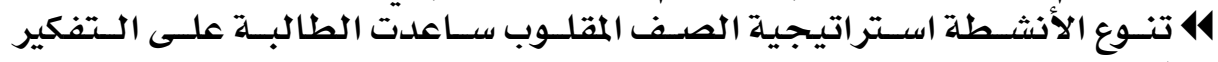

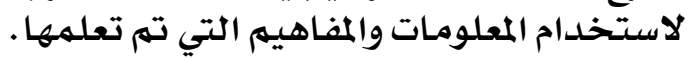

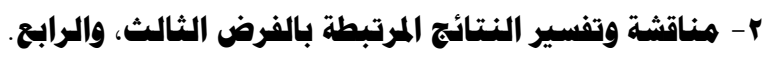

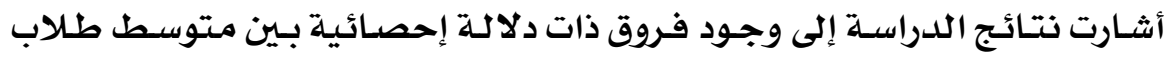

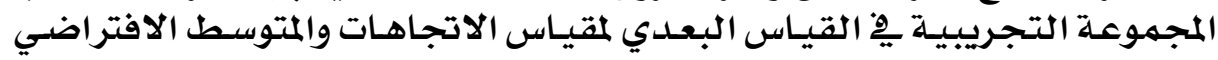

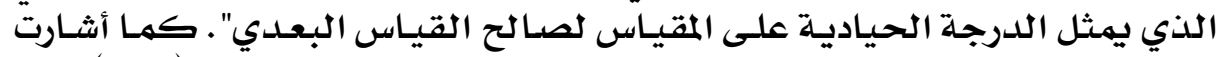

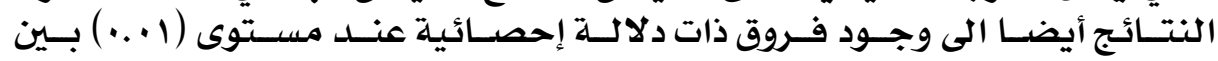

\section{$1 \wedge \wedge$}




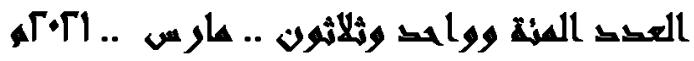

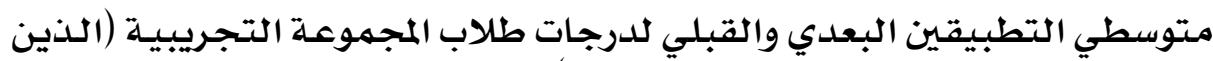

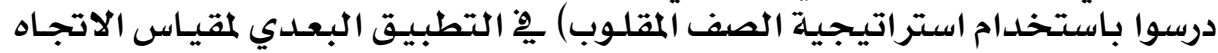

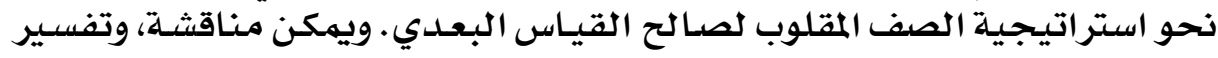

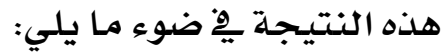

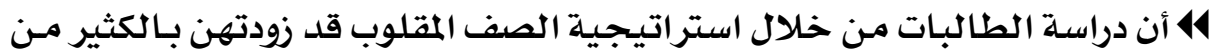

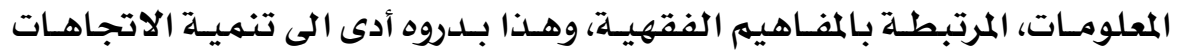

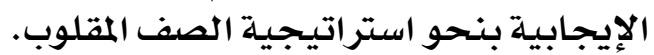

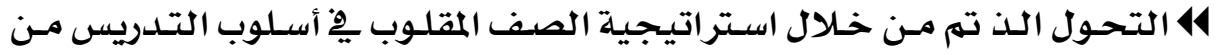

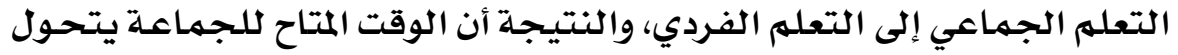

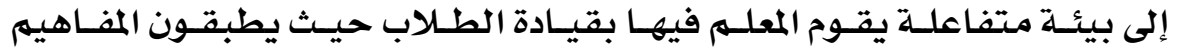

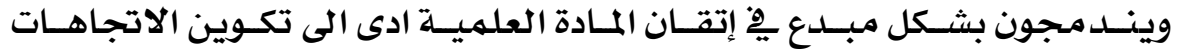
الإيجابية نحوها.

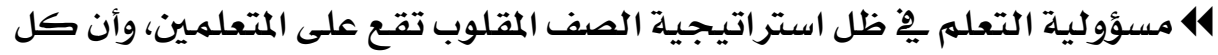

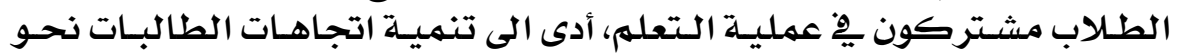

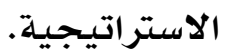

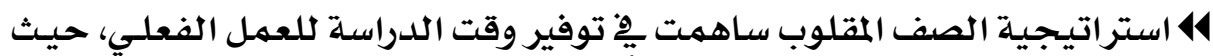

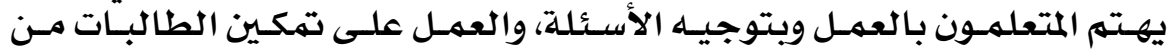

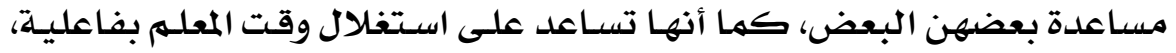

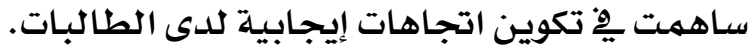

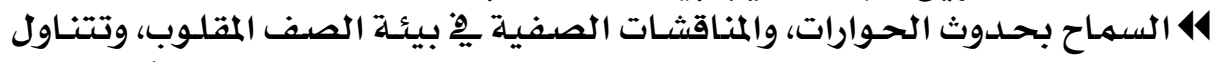

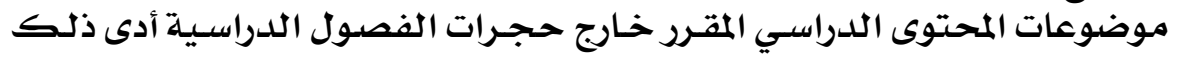

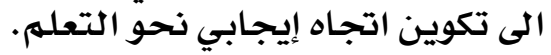

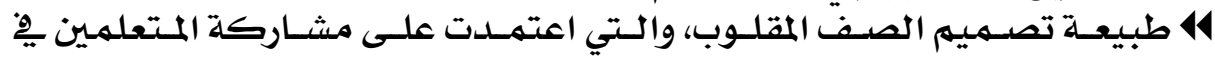

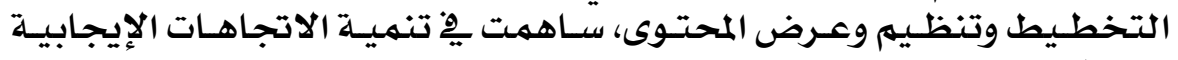
نحو الاستراتيجية. 414

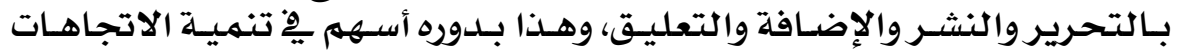

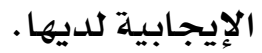
14 مشـاركة المعرفة فياستراتيجية الصف المقلوب سـاهمت يِّ تنميـة الاتجاهـات

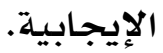

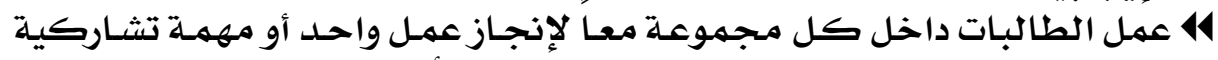

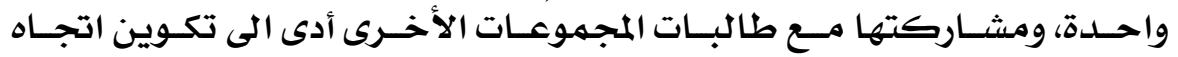

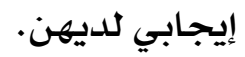

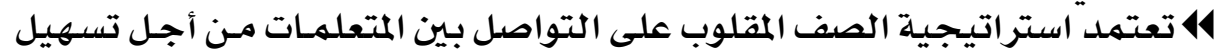

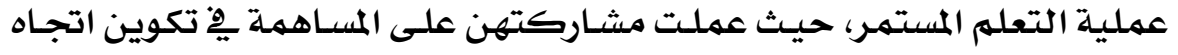
إيجابي نحو الاستراتيجية.

\section{$1 \wedge 9$}




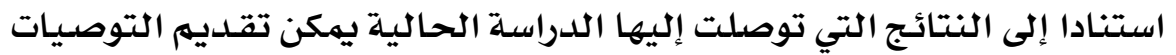
التتالية:

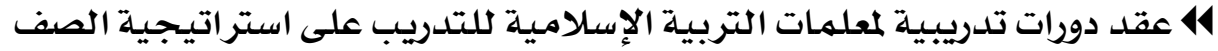

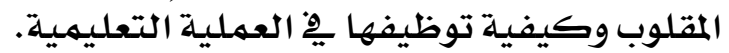

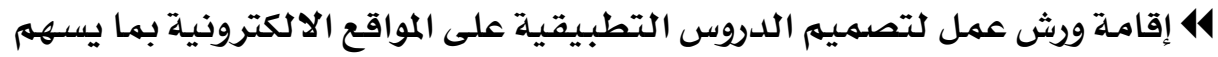

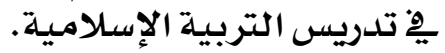

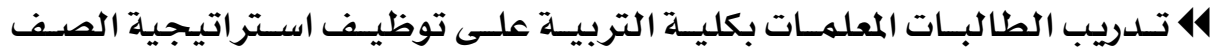
المقلوبفي العمليـة التعليهيـة التبلية.

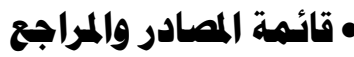

$$
\begin{aligned}
& \text { - القرآن الكريه. } \\
& \text { - الحديث الشريف. }
\end{aligned}
$$

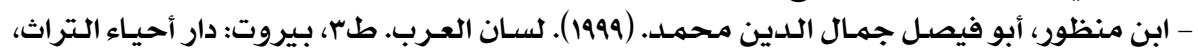
مؤسست التاريخ العربي.

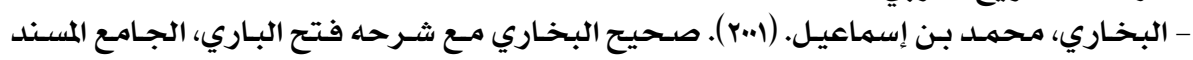

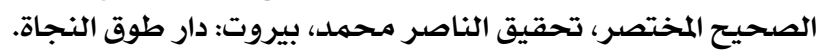

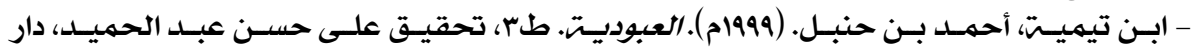

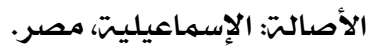

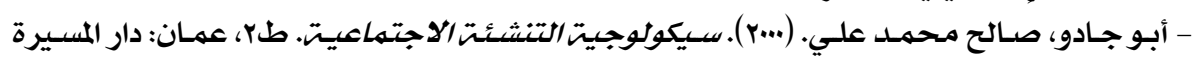

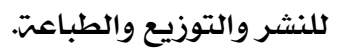

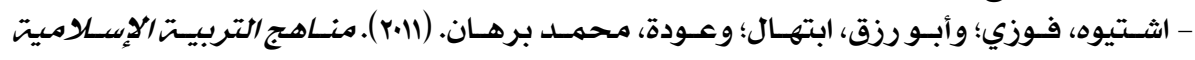

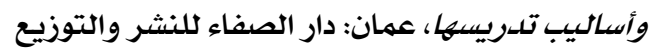

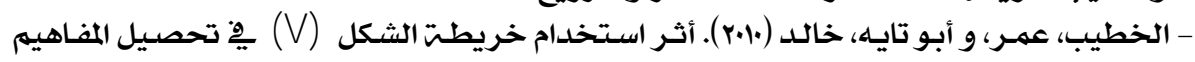

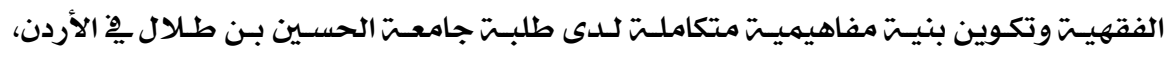

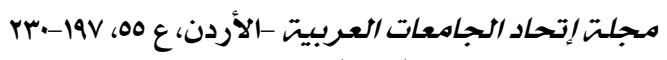

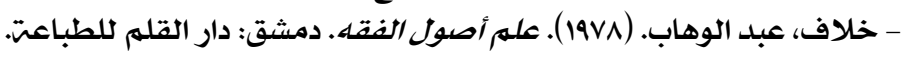

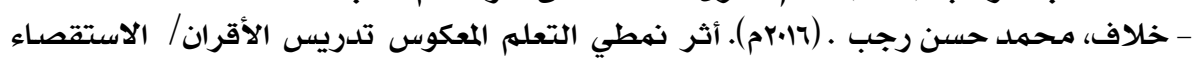

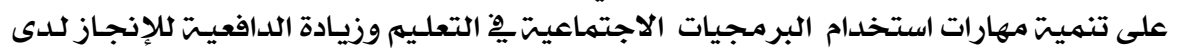

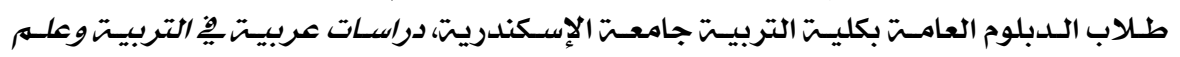

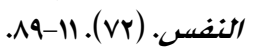

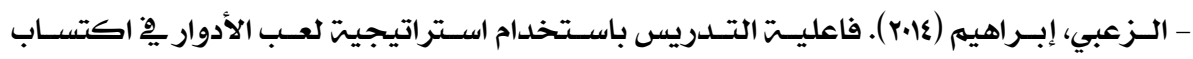

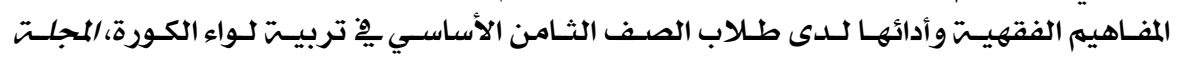

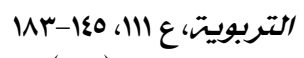

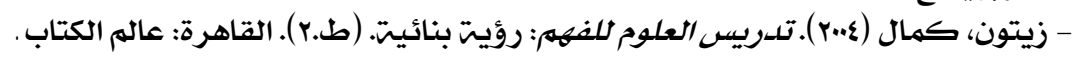

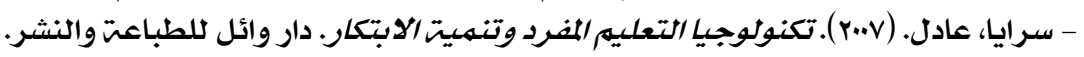




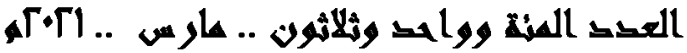

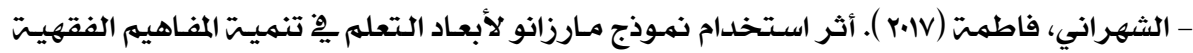

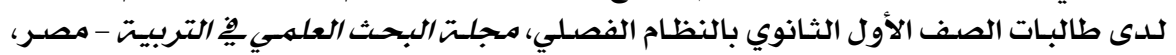

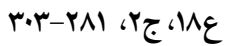

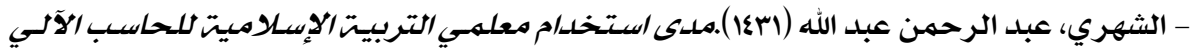

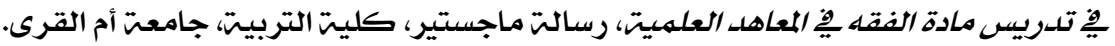

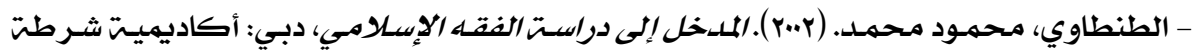

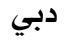

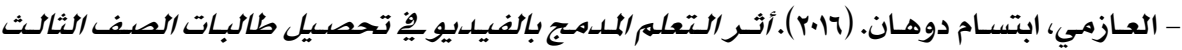

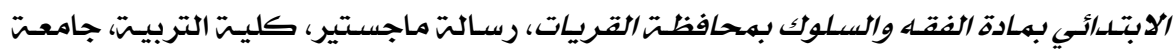
اليرموك. - علام، صلاح (ب.بr). القياس والتقوبيم التربوي والنفسـي. أساسـياته وتوجهاتـه المعاصـرة، القـاهرة: دار الفكر العربي.

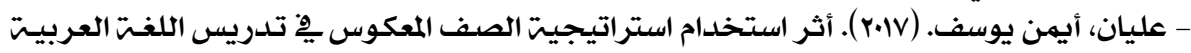

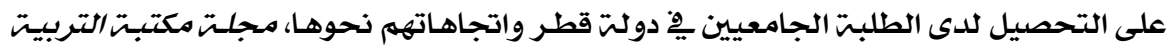

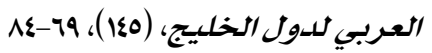

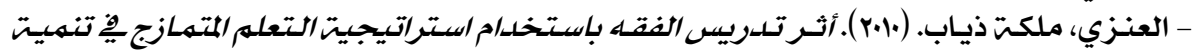

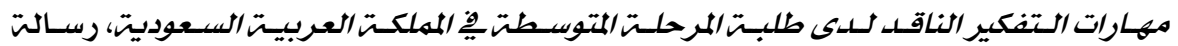

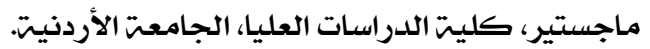

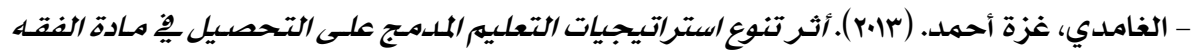

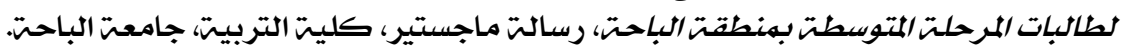

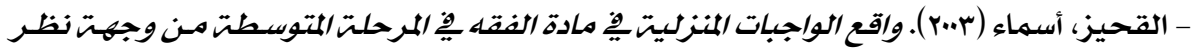

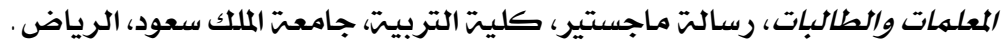

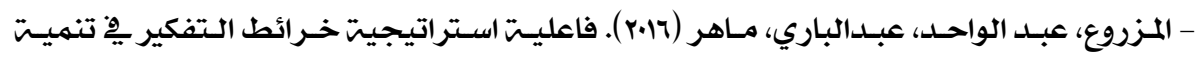

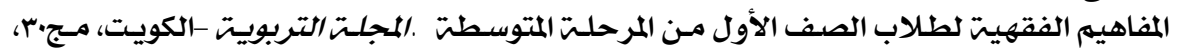
$\varepsilon 1 \cdot-r \leqslant \vee ، 11 \wedge \varepsilon$

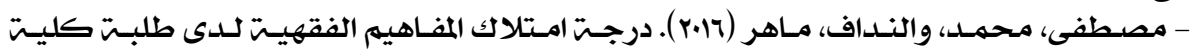

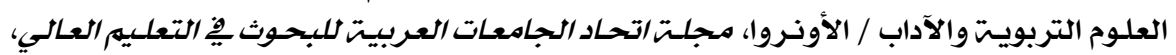

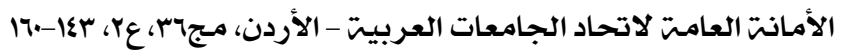

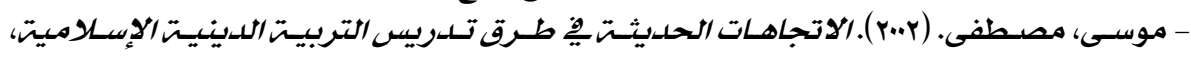

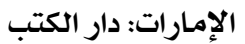

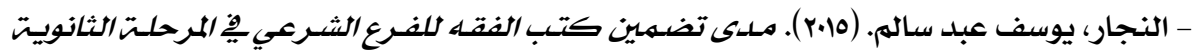

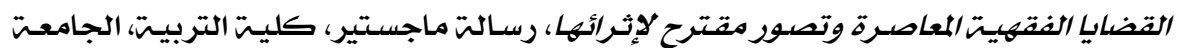
الإسلاميتة، غزة، فلسطين

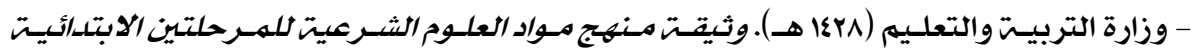

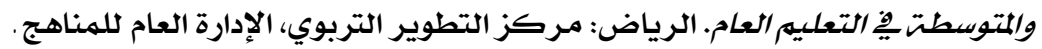

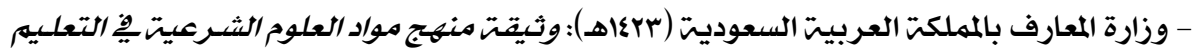

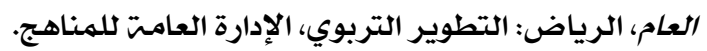




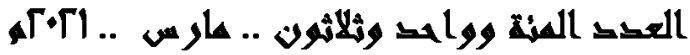

- Bergmann, J., \& Sams, A. (2012). Flipping the classroom. Education Horizon, 90 (1), 5-7.

- Berrett 'D. (2012). How 'flipping' the classroom can improve the traditional lecture. The Chronicle of Higher Education. 58 (21) 16-18.

- Strayer, J. (2007). The Effect of the classroom Flip on the Learning Environment: A Comparison of Learning Activity in A Traditional Classroom and A flip Classroom that used an Intelligent Tutoring System. Unpublished PHD dissertation. Philosophy Graduate School the Ohio State University, Ohio. 